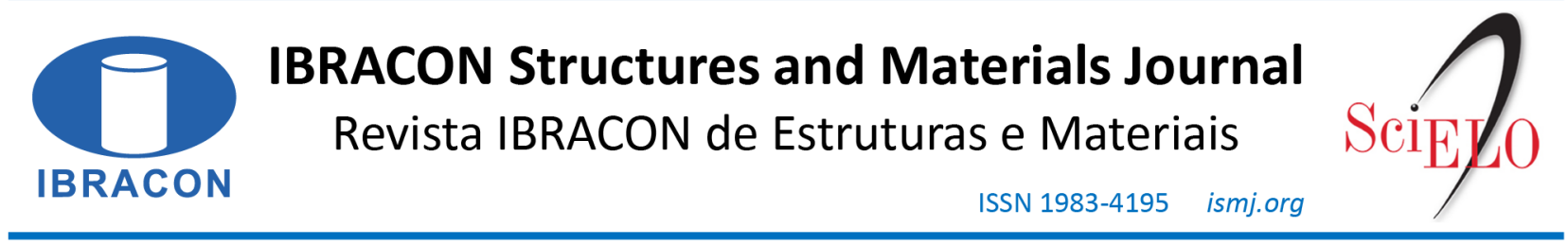

ORIGINAL ARTICLE

\title{
Development of Brazilian highway live load model for unlimited fatigue life
}

\section{Desenvolvimento do modelo rodoviário brasileiro de carga móvel para vida útil ilimitada à fadiga}

\author{
Anselmo Leal Carneiro ${ }^{\mathrm{a}, \mathrm{b}}$ (i) \\ Enson de Lima Portela ${ }^{c}$ (D) \\ Túlio Nogueira Bittencourt ${ }^{\mathrm{a}}$
}

${ }^{a}$ Universidade de São Paulo - USP, Escola Politécnica, São Paulo, SP, Brasil

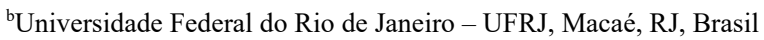

'Instituto Federal do Ceará - IFCE, Departamento de Construção Civil, Fortaleza, CE, Brasil

Received 21 February 2019

Accepted 30 January 2020

\begin{abstract}
This work studies the fatigue live load model used in Brazil for highway bridges. Using the unlimited fatigue life approach, the current live load model is evaluated in relation to the actual traffic and a new fatigue live load model is proposed. Weigh-in-motion (WIM) stations data on two important Brazilian highways are used. The main structural analysis performed in this paper consider the bridges as box girders or multiple girders. The ratio between real traffic and the live load model load effect (bias factor) are determined for single and continuous spans in terms of bending moment and shear force. It is found that the bias factor of the current live load can vary a lot and may not ensure unlimited fatigue life. The proposed model, on the other hand, presents more uniform bias factors and is in accordance with the unlimited fatigue life approach for the WIM data.
\end{abstract}

Keywords: highway bridges, fatigue, live load, weigh-in-motion.

\begin{abstract}
Resumo: Este trabalho estuda o modelo de carga móvel utilizado no Brasil para a verificação de fadiga em pontes rodoviárias. Mediante a abordagem de vida útil ilimitada à fadiga, avalia-se o trem tipo vigente em relação ao tráfego real e propõe-se um novo modelo de carga móvel de fadiga. São utilizados dados de estações de pesagem em movimento (weigh-in-motion - WIM) localizadas em duas importantes rodovias brasileiras. São consideradas estruturas típicas de pontes em grelha e seção celular, onde as razões entre as solicitações do tráfego e do modelo de carga móvel (fatores viés) são determinadas para vãos biapoiados e contínuos em termos de momento fletor e força cortante. Verifica-se que o trem tipo atual apresenta considerável variação nos fatores viés e pode não assegurar vida útil ilimitada à fadiga. O modelo proposto, por outro lado, apresenta fatores viés mais uniformes e condiz melhor com abordagem de vida útil ilimitada à fadiga para o tráfego obtido das estações WIM.
\end{abstract}

Palavras-chave: pontes rodoviárias, fadiga, carga móvel, pesagem em movimento.

How to cite: A. L. Carneiro, E. L. Portela, and T. N. Bittencourt, "Development of Brazilian highway live load model for unlimited fatigue life," Rev. IBRACON Estrut. Mater., vol. 13, no. 4, e13407, 2020, https://doi.org/10.1590/S1983-41952020000400007

\section{INTRODUCTION}

The highway bridges are susceptible to the fatigue as they are subjected to live load from the traffic. Fatigue can be described as the process by which the damage in a given material is generated by stress fluctuations. This damage may result in the structural rupture of the component, even if the highest applied stress is below the elastic limit of the material. 
The live load of the ABNT (Brazilian Technical Code Association) NBR 7188 [1], comes from a retired German code that, according to Pfeil [2], used a design vehicle corresponding to the army tank, surrounded by distributed load. For the fatigue load, a weighting factor is used for the current model. This design load, nonetheless, was not proposed considering the traffic reality in Brazil. Whereas the Brazilian code presents a single model of fatigue load, the main international codes, for instance the Eurocode [3] and AASHTO LRFD [4], present a fatigue live load model for both limited and unlimited fatigue life.

In Brazil, the main studies about live load on highway bridges are focused on the Ultimate Limit State (ULS). Fatigue studies can be found in Baroni [5], Rodrigues et al. [6] and Santos and Pfeil [7]. Most studies in Brazil use data from static weighing stations to consider traffic. It is important to remark, however, that static stations can present biased data, since the measurement methodology does not provide total reliability. Moreover, the overloaded vehicles can trace alternative routes and the data is not collected 24 hours a day, in days and months in a row.

Baroni [5], through the analysis of four vehicles database on a Brazilian highway, warns about the possibility of shortening the service life of short span concrete bridges (between $10 \mathrm{~m}$ and $20 \mathrm{~m}$ ). Rodrigues et al. [6] evaluate the reliability indexes of short span concrete bridges $(7 \mathrm{~m}, 10 \mathrm{~m}$ and $13 \mathrm{~m})$, considering the Ultimate Limit State and fatigue. Using 204 days of data from São Paulo weighing stations in 2005, the authors verify that safety levels, especially in relation to fatigue, fall short the desired levels. Santos and Pfeil [7], considering steel bridges submitted to the passage of vehicles registered at weighing stations, report a preliminary proposal of live load model for a limited fatigue service life and evaluate the proposed model by analyzing the fatigue service life of a connecting detail of the metallic structure.

This research studies the live load model used in Brazil to verify the fatigue in highway bridges. Through the unlimited fatigue life approach, the current live load model is evaluated in relation to actual traffic and a new fatigue live load model is proposed. To consider the actual traffic, data from weigh-in-motion (WIM) stations are used. Two stations are considered, one is located in BR-381 highway (also known as Fernão Dias, which connects the states of São Paulo and Minas Gerais) and the other one in BR- 290 (also known as Osvaldo Aranha, in the state of Rio Grande do Sul). Typical structures as box girders or multiple girders are considered. The ratios between traffic and Brazilian model load effects (bias factors) are determined for single and continuous spans, in terms of bending moment and shear force. These bias factors are also calculated for the proposed model.

\section{FATIGUE IN HIGHWAY BRIDGES}

Fatigue occurs due to stress fluctuations from in-service variable loads that, after a certain number of cycles, may lead to fracture of the material. Thus, it can be said that, from the point of view of the loads, fatigue has a character of Service Limit State and, from the point of view of the resistance, has a character of Ultimate Limit State. Normative codes, in general, behave towards the phenomenon in a particular way, calling it the Fatigue Limit State.

Stress ranges with high amplitudes require low number of cycles to fail the material, while stress ranges with low amplitudes require a high number of cycles for failure. These two regimes are known as low cycle fatigue (LCF) and high cycle fatigue (HCF), respectively. Low cycle fatigue is characterized by stress cycles close to the ultimate strength of the material. For bridge structures, the stress cycles from traffic are generally lower than the strength of the material, requiring a high number of cycles to cause the rupture of the structure due to fatigue. Thereby, in general, fatigue in bridges due to traffic is related to high cycle regime.

\subsection{Methods of verification}

In order to determine the fatigue strength, the $\mathrm{S}-\mathrm{N}$ curve is used. This curve is a plot of the stress range magnitude $(\mathrm{S})$ and the number of cycles to failure $(\mathrm{N})$. Figure 1 shows two S-N curves for reinforcing bars embedded in concrete beams. It is important to mention that besides the stress range, there are many variables that affect the number of cycles to failure, including bar diameter, bar curvature, type of bar (ribbed or flat), etc.

In Figure 1, it is possible to notice that around one million cycles the curves tend to horizontal, indicating a fatigue limit. According to ACI 215R-74 [8], the stress range associated with the steeper or flatter part of the curves refers to the finite or "infinite" fatigue life, respectively. This limit, below which the fatigue rupture does not happen even for a large number of stress cycles, is called Constant Amplitude Fatigue Limit (CAFL).

It is important to note, however, that, unlike reinforcing bars, concrete does not present CAFL. For highway bridges, Wassef et al. [9] considered a hundred million cycles to determine the stress range corresponding to the unlimited concrete fatigue life . 


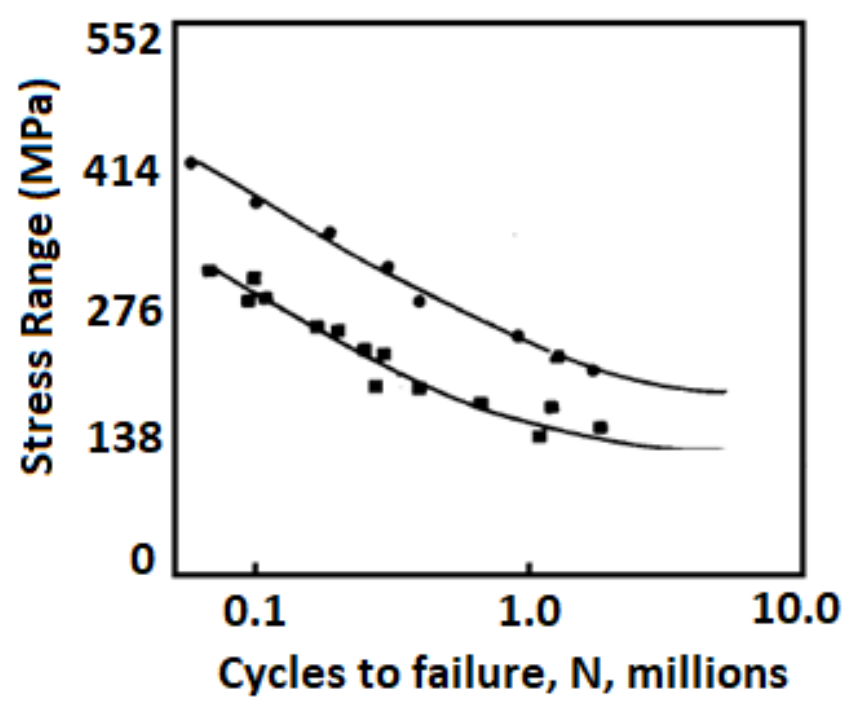

Figure 1. S-N curves for reinforcing bars (adapted from ACI 215R-74 [8]).

If the maximum stress range generated by the load is lower than the CAFL value, the fatigue verification will be guaranteed and the structure will have a fatigue life longer than that required in the design, as long as its original state of full integrity is maintained. This procedure, known as unlimited fatigue life, is used in AASHTO LRFD [4] for concrete bridges. In the calibration of this code, Wassef et al. [9] calibrated the live load model to a bending moment value of traffic that has a $0.01 \%$ probability of being exceeded. According to the authors, this moment is related to the maximum stress range that corresponds to the unlimited fatigue life.

Eurocode 1 [3] presents two live load models for unlimited fatigue life. According to the code, they are applicable only for steel structures. There is a contradiction between Eurocode 1 [3] and AASHTO LRFD [4] in this matter. Sanpaolesi and Croce [10], which discuss the Eurocode 1 [3], present two ways to estimate the maximum stress range corresponding to unlimited fatigue life. One of them considers the maximum stress range as being responsible for $99 \%$ of the total damage resulting from the entire stress range from the real load spectra below the maximum stress range. The other one considers the maximum stress range, as the one which is exceeded 50000 times in a hundred-year design service life.

The fatigue verification can also be limited to the design service life of the structure, using the equivalent damage method. Santos and Pfeil [7] explain that in this method, the design load must have the characteristic of generating, for a prefixed number of cycles, the same damage that would be generated by the load spectra during the design service life of the structure. With the appropriate weighting coefficients, the verification is performed by comparing the stress range of the live load model with the fatigue strength obtained from the S-N curves. This method, however, is not considered in this paper.

The equivalent damage method is considered in AASHTO LRFD [4] and Eurocode 1 [3] for steel bridges and concrete bridges, respectively. Wassef et al. [9] emphasize that this method should not be used to verify fatigue in concrete and reinforcement. There is a contradiction between Eurocode 1 [3] and AASHTO LRFD [4] in this matter. As reported by Eurocode 1 [3], models for limited and unlimited life are not numerically comparable. The Eurocode 1 [3] presents three models for limited fatigue life.

\subsection{Brazilian live load model}

The Brazilian live load model of NBR 7188 [1] is shown in Figure 2, with the concentrated and distributed loads. The TB450 values ("TB" refers to the Brazilian live load model and " 450 " is the total vehicle weight, in $\mathrm{kN}$ ) must also be pondered by the vertical impact coefficient (CIV, in Portuguese) and, when it's necessary, by the number of lanes coefficient (CNF, in Portuguese) and the additional impact coefficient (CIA, in Portuguese). The live load assumes any position on the entire highway with the wheels in the most unfavorable position, considering shoulders and clearances. The distributed load must be positioned in the most unfavorable condition, regardless the road lanes. 


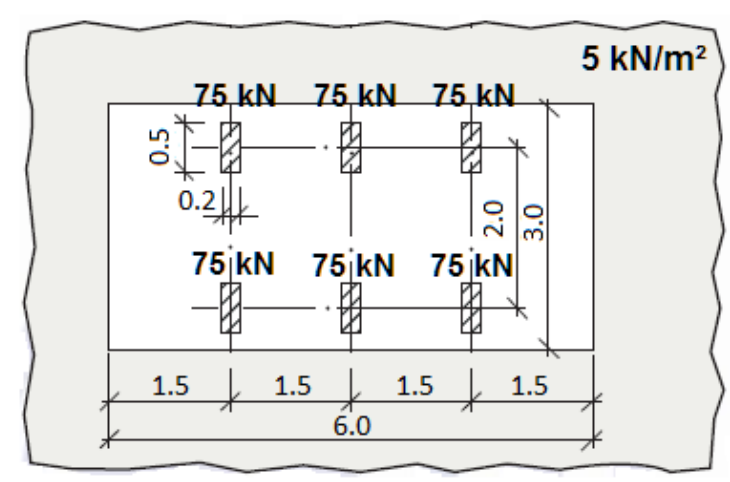

Figure 2. Brazilian live load model, dimensions in meters (adapted from NBR 7188 [1]).

NBR 6118 [11] establishes the reducing factor of 0.5 to be implemented in the model for fatigue verification in bridge girders. According to the code, the fatigue verification in reinforcement will be satisfied if the maximum calculated stress range, $\Delta \sigma_{s}$, satisfies Equation 1,

$\gamma_{f} \Delta \sigma_{s} \leq \Delta f_{s d, f a d}$

where $\gamma_{f}=1.0$; and $\Delta f_{s d, f a d}=$ characteristic fatigue strength for $2 \times 10^{6}$ cycles.

According to Laranjeiras [12], the value of $2 \times 10^{6}$ cycles was also used in the German code (DIN 1045, 1989) and the American one (ACI 343R, 1986). It is worth noting that, according to Figure 1, the S-N curves tend to horizontal at around one million cycles indicating unlimited fatigue life.

For fatigue verification in steel girders with up to 100-m span, the NBR 16694 [13] also establishes the factor of 0.5 . The NBR 8681 [14] also indicates the reducing factor of 0.5 for girders up to 100-m span. According to Laranjeiras [12], this value was provided in a retired German code (DIN 1075, 1988), where the live load was similar to the Brazilian one.

\section{WEIGH-IN-MOTION (WIM)}

\subsection{Description of the system and WIM stations}

Regarding the relevance of actual traffic, this work uses vehicle records obtained from high speed weigh-in-motion stations (HS-WIM), as shown in Figures 3 and 4. The system is installed on the road lanes, and vehicles are registered with no need to stop or to lower their speeds. In general, the system consists of lines of piezoelectric sensors, inductive loops, temperature sensor and a device to collect and analyze the records (Figure 5). Inductive loops detect vehicles and measure the distance between axles and speed, while piezoelectric sensors are responsible for weighting. In this work, data from the BR-381 (Fernão Dias, SP-MG) and BR-290 (Osvaldo Aranha, RS) stations are used. Figure 6 shows the final layout of the system in both highways.

In BR-381, the system is installed in two road lanes in the same direction (Minas Gerais to São Paulo) and the data are sent to the Structures and Structural Materials Laboratory of the Polytechnic School of the University of São Paulo - LEM / USP. The traffic statistics presented in this work cover the period from September 2015 to August 2017, with daily records (data from February to May 2016 are missing). The station is currently in operation.

In the BR-290 station, the system was installed between the cities of Porto Alegre and Osório, in 2013. The highway has three lanes in the same direction, however the sensors were installed only in the two lanes on the right, where most trucks circulate. The data used in this work covers the period from March to June 2014, summing 79 days (there are days without records). The station is no longer in operation. 

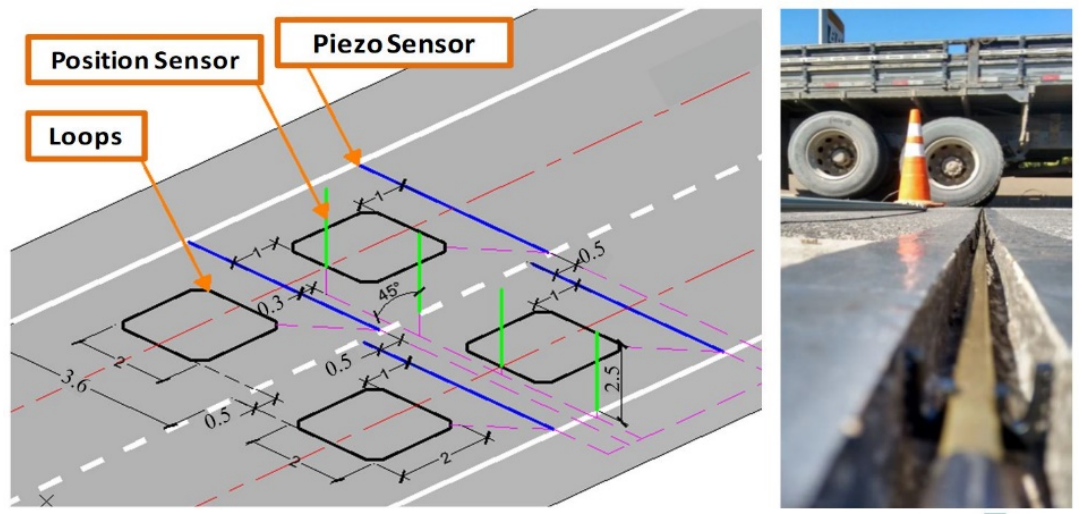

Figure 3. HS-WIM system in BR-381 (MG-SP) and weighting sensor before grout (adapted from Portela [15]).

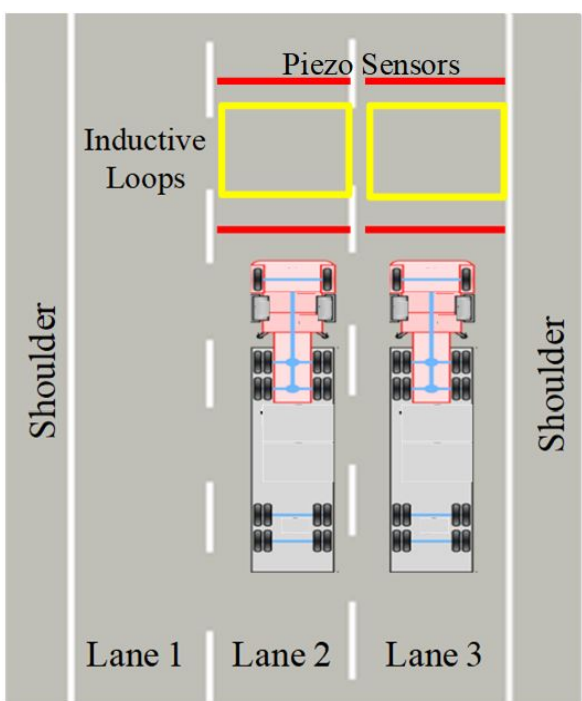

a)

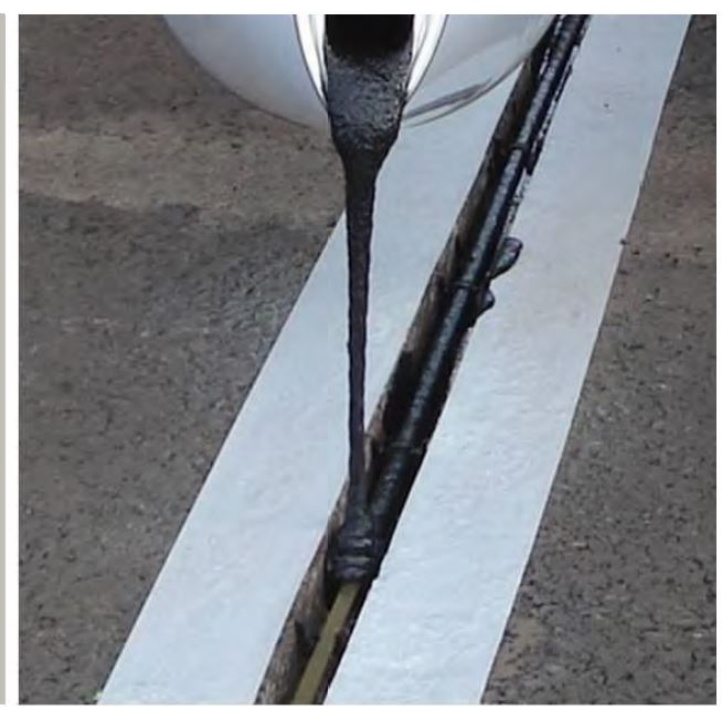

b)

Figure 4. a) HS-WIM system in BR-290 [15]; b) weighting sensor with grout [16].
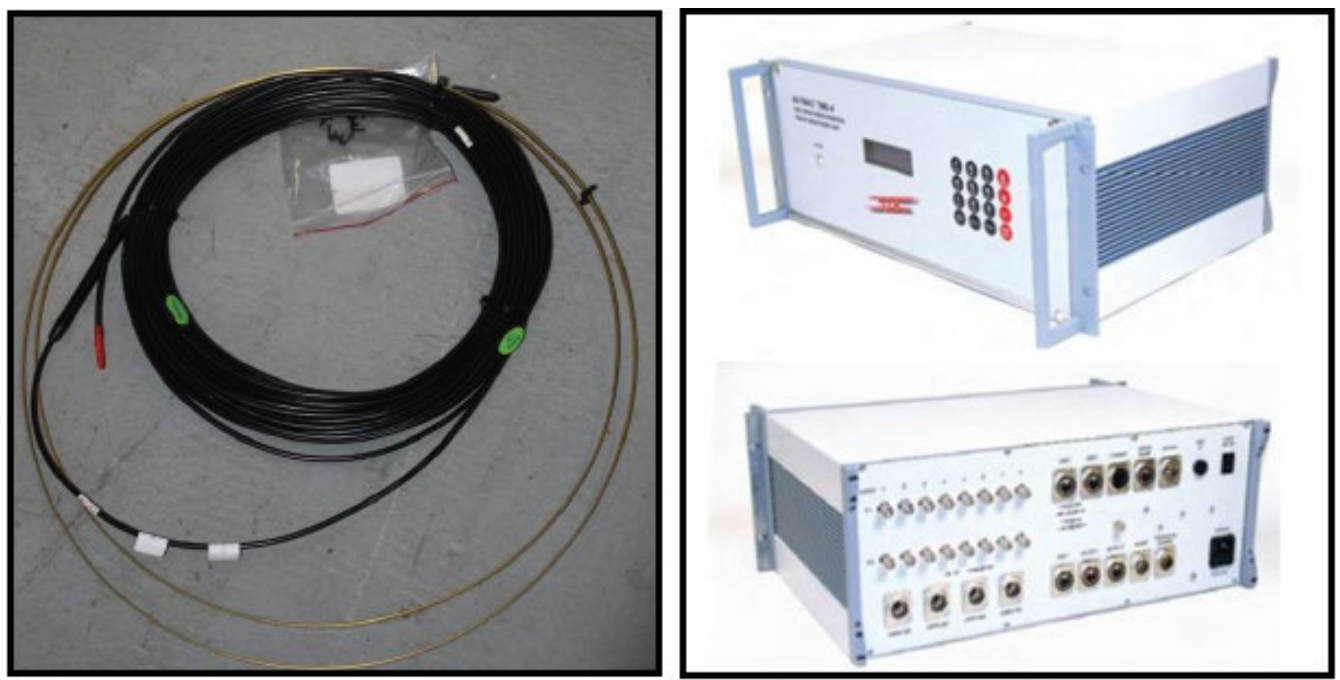

Figure 5. Sensors and data collecting system from BR-290 (adapted from Brito and Bock [16]). 


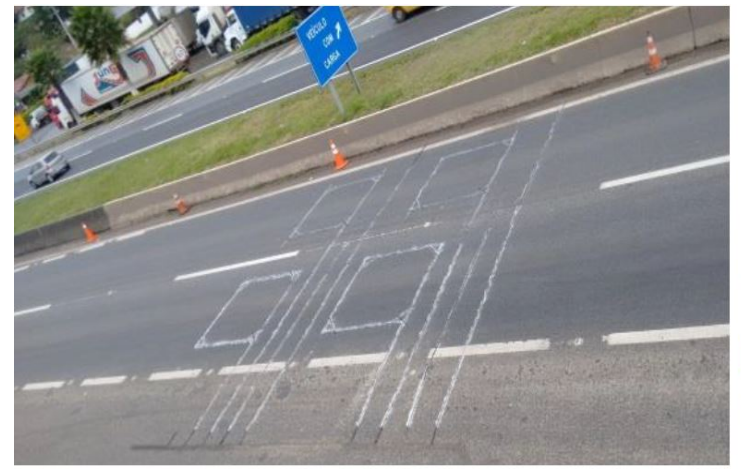

a)

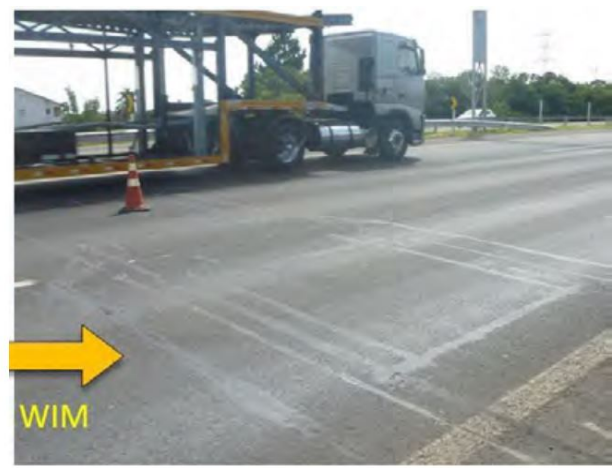

b)

Figure 6. Final appearance of HS-WIM system in both highways: a) BR-381 [15]; b) BR-290 [16].

For each vehicle that passes through the sensors, the system provides information, such as day, hour, lane, speed, total length, total weight, axle spacing and axle weight. In this work, the records are analyzed using Microsoft Excel spreadsheets. Table 1 shows the organization of the data, where each line corresponds to a truck. The outline of the five most frequent classes obtained from WIM are shown in Figure 7, with the respective legal weights ( $5 \%$ of tolerance).

Table 1. WIM data in the spreadsheets.

\begin{tabular}{ccccccccccccc}
\hline Day & Hour & Lane & $\begin{array}{c}\text { Speed } \\
(\mathbf{K m} / \mathbf{h})\end{array}$ & DNIT & $\begin{array}{c}\text { Total } \\
\text { length }(\mathbf{m})\end{array}$ & $\begin{array}{c}\text { Total } \\
\text { weight } \mathbf{( k N )}\end{array}$ & $\begin{array}{c}\mathbf{d 1 2} \\
(\mathbf{m})\end{array}$ & $\begin{array}{c}\mathbf{d 2 3} \\
(\mathbf{m})\end{array}$ & $\begin{array}{c}\text { P1 } \\
(\mathbf{k N})\end{array}$ & $\begin{array}{c}\text { P2 } \\
(\mathbf{k N})\end{array}$ & $\begin{array}{c}\text { P3 } \\
(\mathbf{k N})\end{array}$ & .. \\
\hline $01 / 15 / 17$ & $01: 28: 41$ & 2 & 90.4 & $2 \mathrm{C}$ & 12.86 & 112.8 & 6.94 & & 36.9 & 75.8 & \\
\hline $01 / 15 / 17$ & $01: 29: 59$ & 2 & 89.0 & $3 \mathrm{C}$ & 10.49 & 157.3 & 5.11 & 1.36 & 36.7 & 65.6 & 54.9 \\
\hline
\end{tabular}

*d12 e d23 are the axle spacing and $\mathrm{P} 1, \mathrm{P} 2, \mathrm{P} 3$ are the axle weight

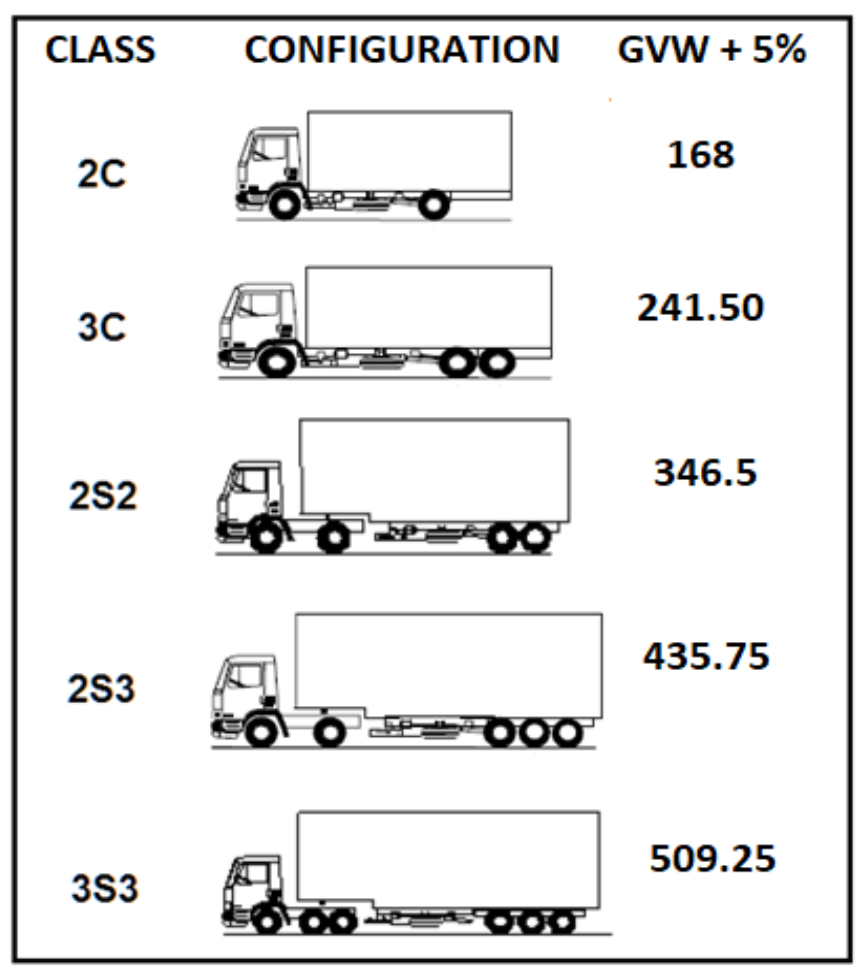

GVW = Gross Vehicle Weight (legal)

Figure 7. Frequent classes with the respective legal weights. 
It is worth noting that the HS-WIM system avoids evasion, as drivers do not notice it. In addition, due to the continuous process of obtaining data (24 hours a day, on consecutive days), the system allows the knowledge of the real frequency of occurrence of the vehicles, which is essential for the fatigue analysis. These particularities give the technology a great advantage over static weighing stations.

Static weighing, on the other hand, is more accurate. As WIM sensors are strongly influenced by temperature, the system must undergo periodic calibrations. In these measurements, a known weight truck passes through the sensors at varying speeds at different times of the day. From July 2015 to August 2017, the Fernão Dias station was calibrated in July 2015, October 2015, February 2016, February 2017 and May 2017. According to Portela [15], the error of the BR-381 system, in relation to the total weight of the trucks, is around $10 \%$. The Rio Grande do Sul station was calibrated in February 2013, as shown by Brito and Bock [16]. HS-WIM is widespread in United States, where the data are widely used to calibrate bridge design codes. In Brazil, nonetheless, considering the reduced number of stations, the use of this system is not common.

\subsection{Filtering process}

Even with calibrations, the system might present incorrect data: weights greater than the maximum traction capacity or smaller than the self-weight are some examples. Furthermore, several data are unnecessary for the study of live load in bridges. Passenger vehicles and light trucks, for instance, can be neglected, in most analyses, due to irrelevant load effect on the bridge. Thus, WIM data needs to be filtered before it can be used. The filtering criteria need to be defined considering the particular characteristics of the Brazilian fleet and may vary according to the analysis need, in other words Ultimate Limit State, service or fatigue.

For service and fatigue analysis, which is the purpose of this work, Wassef et al. [9] explain that the frequency of occurrence of loads is essential, it means the load spectra. In this case, heavy trucks with fewer frequencies have little influence on the analysis and can even be ignored. Light trucks also make no significant contribution. Among the 14 criteria used in Wassef et al. [9], a type of filter is designed to eliminate trucks with a total weight less than $90 \mathrm{kN}$. As reported by Laranjeiras [12], trucks weighing less than $70 \mathrm{kN}$ accumulate fatigue damage that is irrelevant to the safety of the structure, even if they are occur many times.

The following list presents, in order, the filters that are applied to the stations considered. The filters were set after a research in the National Department of Transportation (DNIT, in Portuguese) resolutions and truck manufacturers catalogs. Vehicles that fit any of the filters have been excluded.

$1-$ GVW $\leq 62 \mathrm{kN}$ (GVW is the total gross vehicle weight);

2- $\mathrm{Pi} \leq 22 \mathrm{kN}$, where "Pi" is the axle weight;

3- $\mathrm{Pd}>320 \mathrm{kN}$, where "Pd" is the weight of double tandem;

4- di $\leq 0.92 \mathrm{~m}$, where "di" is the distance between axles;

5- $\mathrm{C}>36 \mathrm{~m}$, where " $\mathrm{C}$ " is the total length of the vehicle;

6- $\mathrm{C}>15.4 \mathrm{~m}$ and $\mathrm{GVW} \leq 104.3 \mathrm{kN}$;

7- $\mathrm{Pi}>180 \mathrm{kN}$;

8- GVW $\geq 1.1 \sum \mathrm{Pi}$ or GVW $\leq 0.9 \sum \mathrm{Pi}$, where " $\sum \mathrm{Pi}$ " represents the sum of the weights of the axles;

9- $\sum \mathrm{di}>\mathrm{C}$, where " $\sum$ di" this represents the sum of the wheelbase;

$10-\mathrm{C}<5 \mathrm{~m}$;

$11-\mathrm{V}>170 \mathrm{Km} / \mathrm{h}$, where " $\mathrm{V}$ " is the vehicle speed;

$12-\mathrm{P} 1>100 \mathrm{kN}$, where "P1" is the weight of the first axle (front);

$13-\mathrm{GVW}>1500 \mathrm{kN}$.

On the Fernão Dias highway, the average number of daily vehicles is 13292 before and 3632 after filtering. On the BR-290 the average number of daily vehicles recorded is 11736 before and 1963 after filtering. It shows that the Fernão Dias highway presents, after filtering, an average amount of daily vehicles $85 \%$ larger than the BR-290. In Figure 8 , the filtering percentages for both stations are shown. The following sub-item presents an overview of traffic composition of the Fernão Dias and Rio Grande do Sul highways after filtering.

\subsection{The current traffic composition}

In terms of the average monthly values of the Fernão Dias highway, the average number of vehicles per day varies from 3043 to 4053 and the respective coefficient of variation range from $21 \%$ to $39 \%$. Compared to the monthly average values of BR-290, the average number of daily vehicles varies from 1619 to 2190 and the respective coefficient of variation range from $30 \%$ to $53 \%$. Tables 2 and 3 show the traffic composition statistics for the five most frequent 
classes of Fernão Dias and BR-290 highways, respectively. It is worth pointing out, nevertheless, that a possible reduction of the minimum weight filter value would increase the frequency of class $2 \mathrm{C}$. Although, in Tables 2 and 3 , only the most frequent classes are presented, this work also considers other classes.

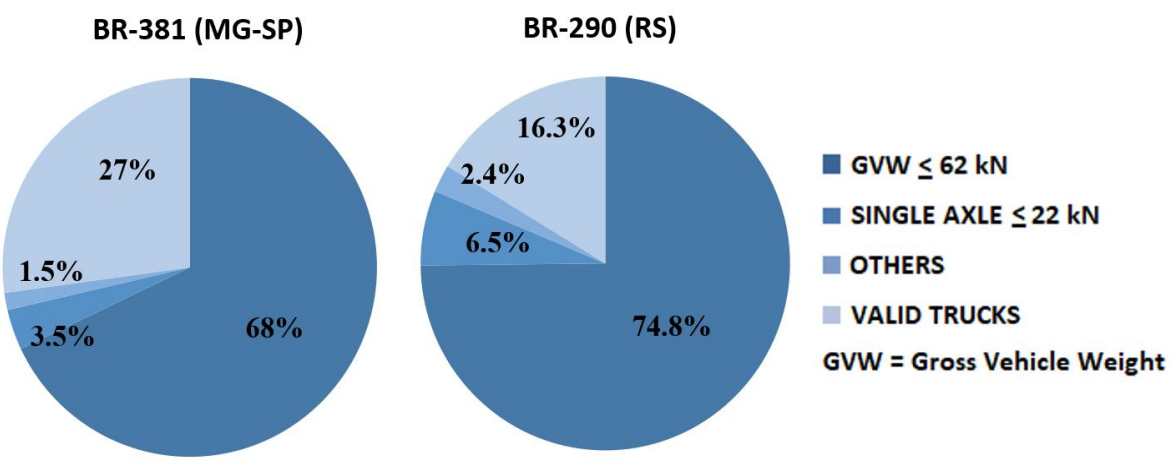

Figure 8. Statistics of filtered data (adapted from Portela [15]).

Table 2. Statistics for main classes of BR-381 (adapted from Portela [15]).

\begin{tabular}{cccccc}
\hline DNIT & Frequency $(\%)$ & $\begin{array}{c}\text { Average } \\
\text { GVW }(\mathbf{k N})\end{array}$ & $\begin{array}{c}\text { Minimum } \\
\text { GVW (kN) }\end{array}$ & $\begin{array}{c}\text { Maximum } \\
\text { GVW (kN) }\end{array}$ & $\begin{array}{c}\text { Average total } \\
\text { length }(\mathbf{m})\end{array}$ \\
\hline 2C & 15.36 & 103.6 & 62.0 & 275.1 & 10.24 \\
\hline 3C & 23.40 & 173.2 & 66.8 & 416.5 & 10.95 \\
\hline 2S2 & 12.96 & 199.1 & 96.7 & 585.0 & 18.45 \\
\hline 2S3 & 9.46 & 337.6 & 124.2 & 712.2 & 17.53 \\
\hline 3S3 & 14.75 & 430.2 & 139.9 & 899.4 & 17.21 \\
\hline
\end{tabular}

GVW: Gross vehicle weight (total)

Table 3. Statistics for main classes of BR-290 (adapted from Portela [15]).

\begin{tabular}{cccccc}
\hline DNIT & Frequency (\%) & $\begin{array}{c}\text { Average } \\
\text { GVW (kN) }\end{array}$ & $\begin{array}{c}\text { Minimum } \\
\text { GVW (kN) }\end{array}$ & $\begin{array}{c}\text { Maximum } \\
\text { GVW (kN) }\end{array}$ & $\begin{array}{c}\text { Average total } \\
\text { length (m) }\end{array}$ \\
\hline 2C & 18.21 & 101.2 & 63.0 & 273.0 & 9.19 \\
\hline 3C & 23.37 & 166.2 & 67.2 & 423.0 & 9.76 \\
\hline 2S2 & 7.45 & 192.1 & 100.0 & 547.0 & 16.67 \\
\hline 2S3 & 10.56 & 318.5 & 121.0 & 660.0 & 17.40 \\
\hline 3S3 & 15.55 & 400.4 & 154.0 & 807.0 & 16.57 \\
\hline
\end{tabular}

GVW: Gross vehicle weight (total)

\section{EVALUATED BRIDGES AND METHODS FOR DETERMINING THE LOAD EFFECTS}

This work examines typical structures of bridges including box girders and multiple girders (Figure 9), which are the most common types considered in typical projects.

The multiple girders bridges were obtained from real projects in the state of Minas Gerais with dates of 2012 and 2013. The highways have two traffic lanes of $3.60 \mathrm{~m}$, two $0.6-\mathrm{m}$ clearances and two New Jersey barriers of $0.4 \mathrm{~m}$. Six bridges with simply supported prestressed girders are considered, without intermediate crossbeams (crossbeams only in the supports), with spans of 14, 16, 18, 28, 37 and 41 meters. The 37-m span has four girders and the others have three girders, as shown in Figure 9. Bridges with spans of 18, 28 and 41 meters were also considered with intermediate crossbeams.

Regarding box girders bridges, one, two, three or four traffic lanes of $3.60 \mathrm{~m}$ are contemplated, where two clearances of $0.6 \mathrm{~m}$ each are also used, as shown in Figure 9. For each box section, spans of 10, 30, 50 and 70 meters are contemplated in simply supported and two-span continuous structures.

For the determination of the longitudinal global load effects in box bridges, it is accepted that the structure is a single beam, homogeneously distributing the forces from the loads on the deck. In this matter, due to the high torsional rigidity of the closed section, it is not necessary to assess the transversal distribution of the load effects. 


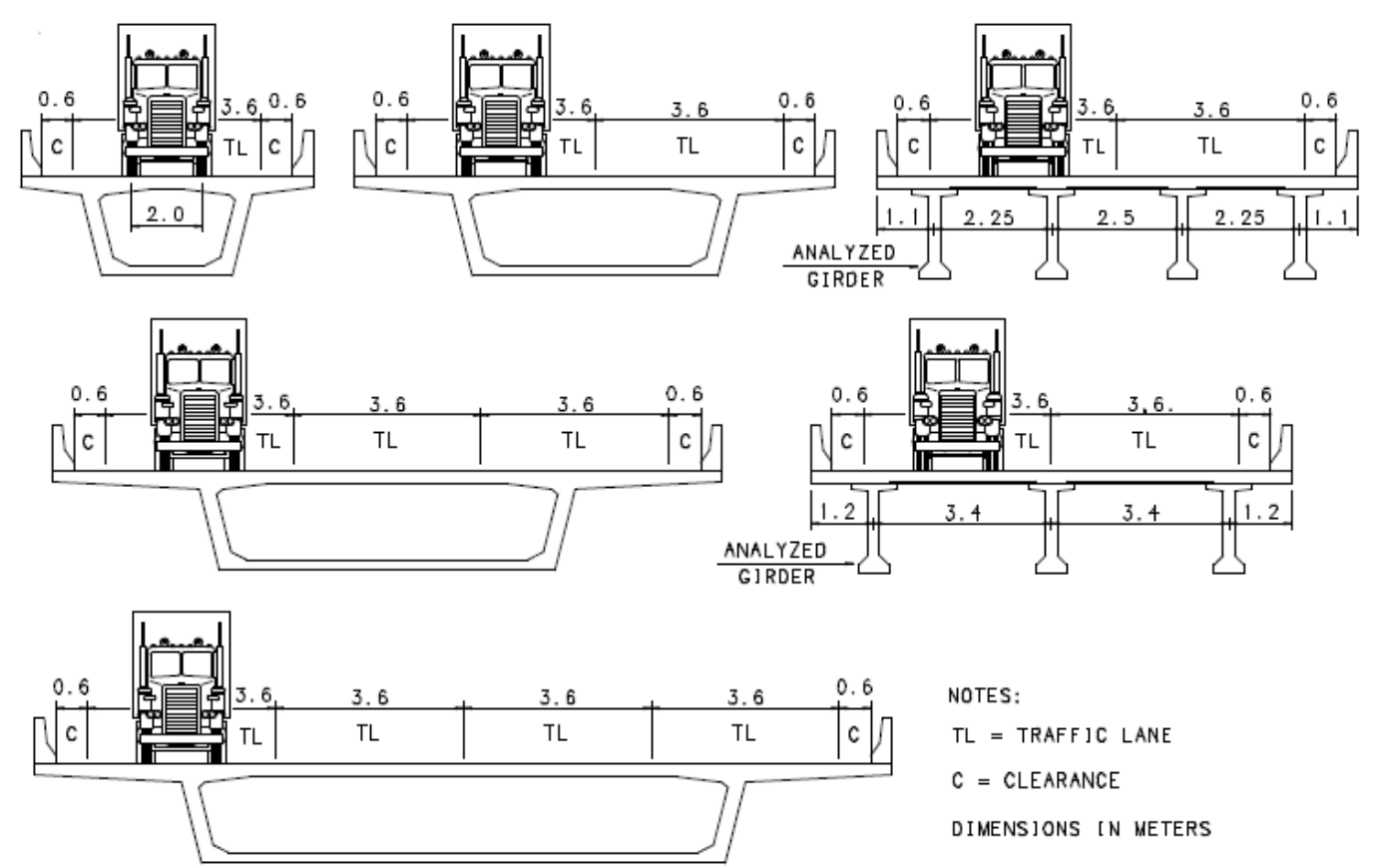

Figure 9. Cross-section of bridges.

On the multiple girders bridges, in contrast, it is necessary to study the girder distribution factors. This work uses the Engesser-Courbon and Fauchart methods for structures with and without intermediate crossbeams, respectively, as presented in Stucchi [17]. For both methods, routines were developed in Microsoft Excel and for the Fauchart method the Ftool structures analysis program [18] was also used.

Regarding to longitudinal analysis for simply supported bridges, which can be multiple girders or box girders, the bending moment at mid-span and the shear force at support are evaluated. In continuous box girder bridges, the bending moment at support is evaluated. In Figure 10, the influence lines, that were implemented in Microsoft Excel, are shown.

\section{DETERMINATION OF TRAFFIC LOAD EFFECT CORRESPONDING TO UNLIMITED FATIGUE LIFE}

To determine the load effects due to current traffic for unlimited fatigue life, this work considers the same approach as in Wassef et al. [9]: the individual passage of vehicles. According to Wassef et al. [9], fatigue analysis requires the frequency of occurrence of loads, in other words, the load spectra. Thus, the authors do not consider the situations of trucks in multiple presence, due to the small probability of occurrence. It must be point out, however, that the consideration of multiple presence is essential for the Ultimate Limit State. This issue, however, is not part of this paper. The multiple presences statistics for the WIM data of Fernão Dias highway are presented in Portela [15].

It is important to add that the present work does not consider the dynamic effect of trucks, that means it is a static analysis in order to evaluate the Brazilian live load model without impact. Dynamic amplification must be studied separately.

In order to compute the distribution of load effect of girder bridges, it is considered that trucks are centered in the traffic lane and the transversal distance between wheels is $2 \mathrm{~m}$, as shown in Figure 9. The exterior girders (close to cantilever slabs) present the highest load effects for both live load model and traffic. Thus, the bias factor for girder bridges are analyzed for exterior girders. Considering that the trucks are centralized in the traffic lane, it appears that, based on the Engesser-Courbon and Fauchart methods, the values of the load effect for exterior girders do not change due to possible changes in the transverse distance between wheels.

The routines for computing the load effect due to the real traffic, according to the influence lines in Figure 10, were implemented in Microsoft Excel spreadsheets that contain the WIM record. The routines were validated with the Ftool program [18] by comparing load effects from different vehicles. In the routines, it is possible to include a value for the transversal load distribution factor, which is 1.0 for box girders. For girder bridges, this factor varied from 0.42 to 0.59 (exterior girders). 


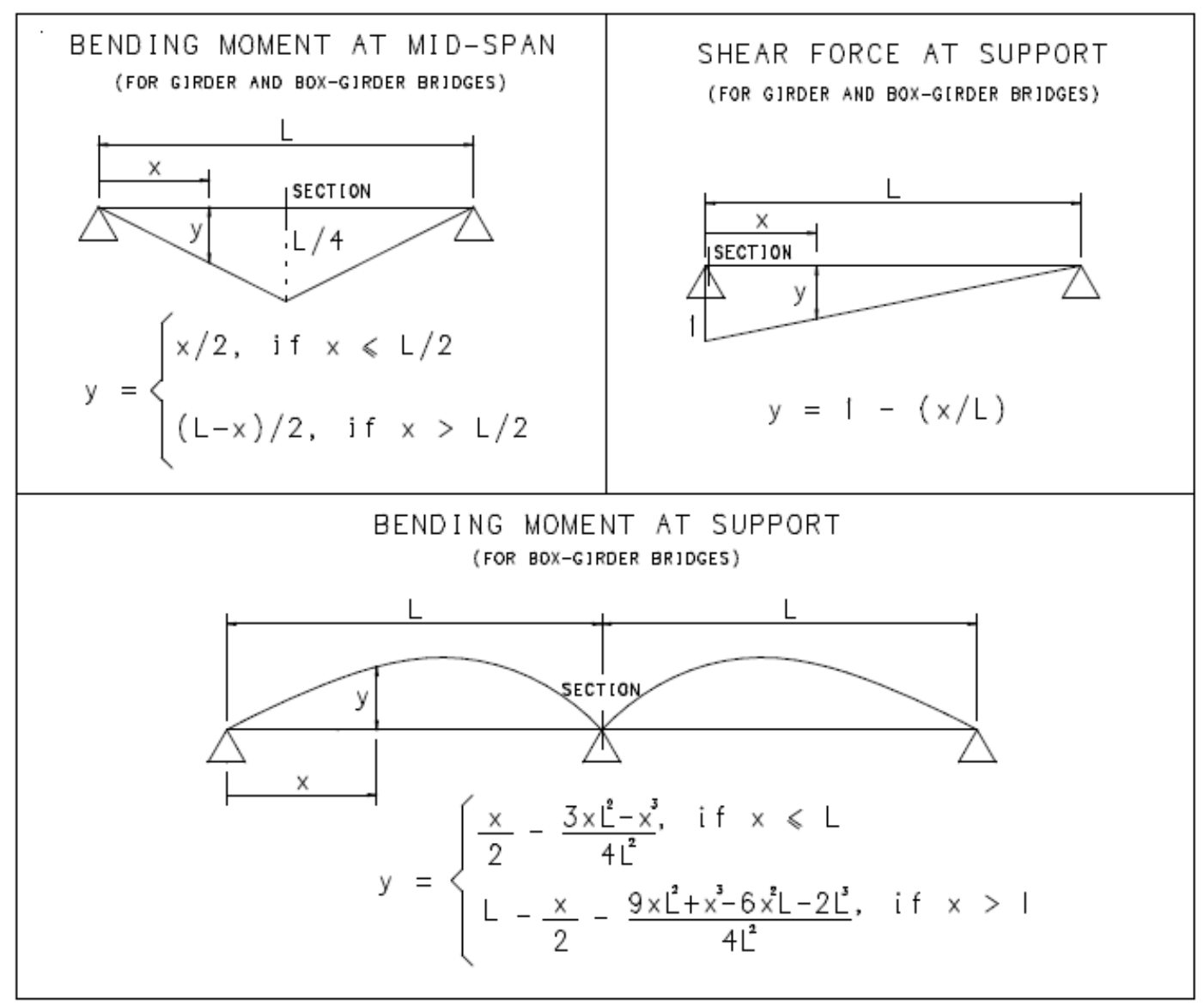

Figure 10. Influence lines.

Similarly to Wassef et al. [9], this work uses the graphical method of the normal probability paper for the statistical interpretation of the data. In this method, the horizontal axis represents the variable and the vertical axis represents the number of standard deviations from the mean value, which is also referred as "standard normal variable" or "z-score". The vertical axis can also be interpreted as the probability of being exceeded. Since " $X$ " is the random variable and "Q" is the number of points in the sample, the graphical construction procedure, according to Nowak and Collins [19], follows the steps:

1- The values of the variable $\mathrm{X}$ are organized in ascending order, assigning to each value an index "i" ranging from 1 to $\mathrm{Q}$. Repeated values are not discarded;

2- for each " $x_{i}$ " value, the accumulated probability is associated to " $p_{i}=\mathrm{i} /(\mathrm{Q}+1)$ ";

3- for each " $p_{i}$ " value, $z_{i}=\Phi^{-1}\left(p_{i}\right)$ is determined, which represents the inverse of the standard normal distribution;

4- ploting the coordinates $\left(x_{i}, z_{i}\right)$.

This procedure is performed on each bridge for each database. The random variable $\mathrm{X}$ corresponds to the load effect (bending moment or shear force) for each truck of WIM data and "Q" represents the number of trucks, after filtering.

The most important property of the normal probability paper is that the plot of a normal random variable is represented as a straight line. Thus, the straighter the plotting of the data, the more accurate the representation as a normal distribution will be. However, even if the curve does not approximate to a normal distribution, some important statistical parameters can be obtained. The intersection of the curve with the zero value of the vertical axis $(\mathrm{z}=0)$ gives the mean value, which corresponds to the probability $p_{i} .=0.5$. The slope of the curve is equal to $1 / \sigma_{x}$, where $\sigma_{x}$. is the standard deviation. Thus, the steeper the curve, the smaller the standard deviation.

For the calibration of the live load model for unlimited fatigue life of AASHTO LRFD [4], Wassef et al. [9] obtain bending moments regarding the $0.01 \%$ probability of being exceeded. This corresponds to the percentage of $99.99 \%$, 
which represents the vertical value $\mathrm{z}=3.8$ on the probability paper. These moments are related to the maximum stress range for unlimited fatigue life.

The approach of Sanpaolesi and Croce [10] for the unlimited fatigue life of Eurocode 1 [3], considers the maximum stress range that exceeds 50000 times in a hundred-year design service life. Therefore, this approach requires contemplating the volume of truck traffic in the future. Rodrigues et al. [6] consider the average daily truck traffic (ADTT) of 5000 vehicles for two lanes. It is worth pointing out that the ADTT for two lanes of BR-381 and BR-290 is 3632 and 1963 vehicles, respectively.

For the BR-381 and BR-290 highways, the Sanpaolesi and Croce [10] approach results in the probability of the load effect being exceeded of $0.027 \%$ for bridges with ADTT $=5000$ and $0.014 \%$ for bridges with ADTT $=10000$. Hence, the value of $0.01 \%$ presented in Wassef et al. [9] meets these values. These probabilities result in close load effects and bias factors. The values presented in this work, for bending moment and the shear force, are related to the probability of $0.01 \%$ of the load effect being exceeded.

In Figure 11, considering data from BR-381 (Fernão Dias Highway), the determination of bending moment at mid-span for the simply supported bridge is shown. The curve shown in Figure 11 consists of several points and each point represents a truck of the database after filtering. As the analysis consider the single trucks, the load effect for box-girder bridges does not change with more lanes. It is worth noting, however, that the respective bias factors are changed according to the number of lanes, since the factor also depends on the live load model.

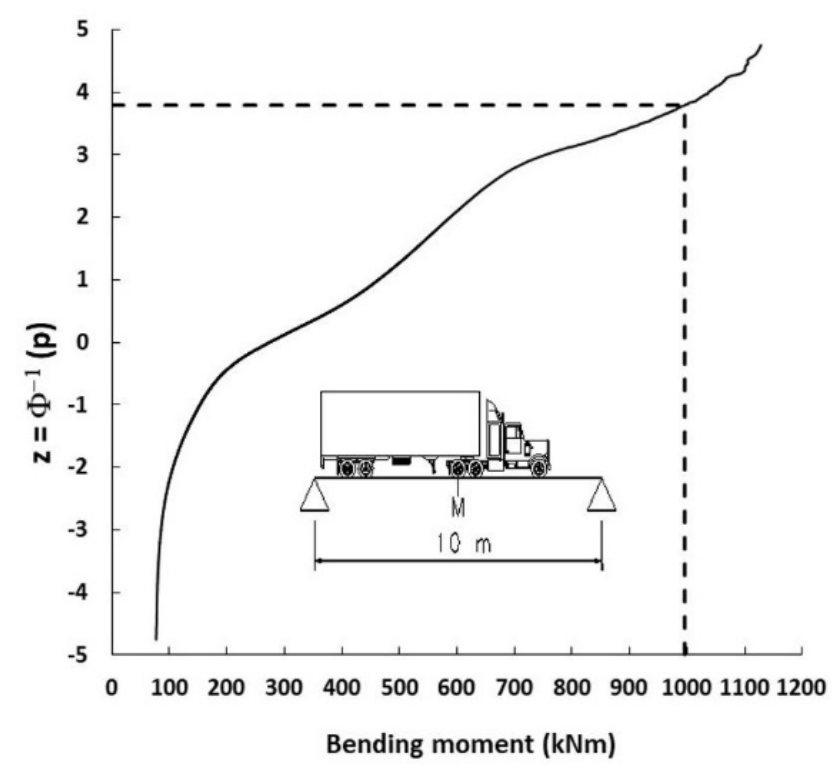

Figure 11. Determination of the load effect on the normal probability paper.

To determine the load effect from Fernão Dias highway, this work uses WIM data from September 2016 to May 2017 (273 days). It was verified that, as long as at least four months of the station are used, the results practically do not change with the increase in the number of months. For BR-290, all four available months are used (March to June 2014). It is important to comment that the possibility of changing the Filter 1 was studied, where the value of $90 \mathrm{kN}$ was tested, as used in Wassef et al. [9]. This change, however, did not significantly alter the load effects related to unlimited fatigue life.

\section{EVALUATION OF THE BRAZILIAN LIVE LOAD MODEL IN RELATION TO REAL TRAFFIC}

To evaluate the Brazilian live load model, the ratio between load effect due to real traffic and live load model are computed. The Brazilian model is considered according to the loads on Figure 2. Impact and weighting coefficients are not contemplated. Thus, the fatigue-reducing factor of 0.5 is assessed according to the bias factors obtained. Factors larger than 0.5 indicate that the Brazilian model falls short of the actual traffic for an unlimited fatigue life. It is worth 
remembering that for girder bridges, the bias factors refer to the exterior girders, since they presented the highest load effects on the structures considered.

Bias factors are presented for bending moment at mid-span of simply supported bridges, bending moment at support of continuous bridges, and shear force at support of simply supported bridges. The load effects were computed for the WIM data and the live load model using the routines developed in Microsoft Excel. To calculate load in the live load model for continuous bridges, the Ftool program [18] was used yielding curved influence lines (Figure 10).

It was considered unnecessary to carry out the analysis for continuous bridges in terms of bending moment near the midspan or shear force at supports. After analyzing some results with the Ftool program [18], it was found that the bias factors of these load effects are very close to the respective values for simply supported bridges. In fact, it's verified, according to Figure 12, that the influence lines for the bending moment at mid-span and the shear force at supports of continuous structures are like those of simply supported structures. Thus, the bias factors of these load effects for simply supported bridges also apply to continuous bridges.

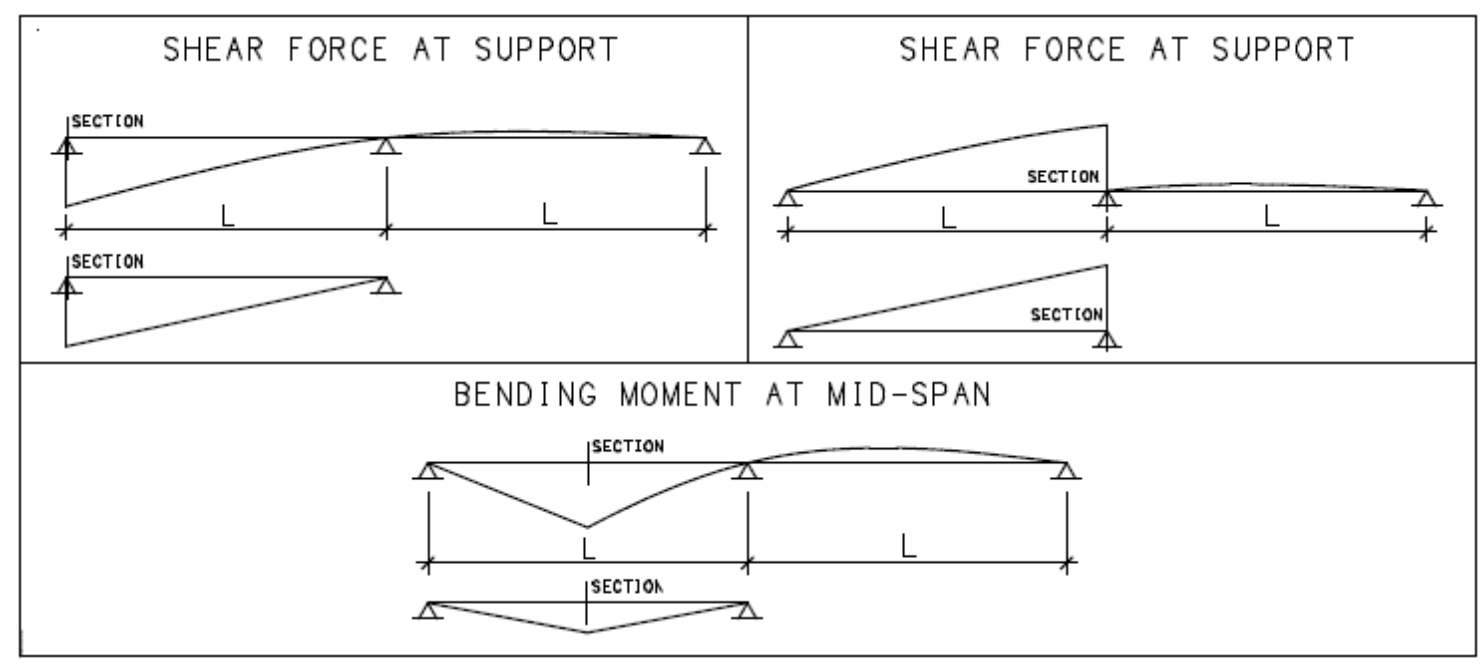

Figure 12. Similar influence lines.

Figures 13 to 20 show the bias factors for the BR-381 (Fernão Dias) and BR-290 highways. It is verified that the bias factors are not uniform, i.e., the current model can cover the real traffic load effects or fall short for it depending on the span length and width of the bridge. In general, the live load model satisfies real traffic for larger spans and multiple lanes bridges. For short span bridges, especially for bridges with one and two lanes, the Brazilian live load model does not satisfies the current truck traffic. Based on these results, it can be observed that is important to develop a Brazilian live load model for unlimited fatigue life, especially for short span bridges.

In the particular case of simply supported girder bridges with two lanes up to 40 meters, which are the most frequent structures on Brazilian highways, the bias factors vary around the mean value close to 0.8, as shown in Figures 19 and 20. Thus, for these structures, the reducing factor of 0.8 for the TB450 corresponds better to the unlimited fatigue life approach.

The fact that the live load model of NBR 7188 [1] is conservative for bridges with larger extensions and wider cross section is mainly due to the distributed load considered along the entire width of the bridge and to its longitudinal extension, in the most unfavorable way. It is worth noting that, if the coefficient of number of lanes (CNF) of NBR 7188 [1] were considered, the bias factors would undergo few changes between approximately $5 \%$ and $10 \%$. The coefficient is 1.05 for one lane, 1.0 for two lanes, 0.95 for three lanes and 0.90 for four lanes.

\section{BRAZILIAN LIVE LOAD MODEL PROPOSAL FOR UNLIMITED FATIGUE LIFE}

To determine the load effect corresponding to the unlimited fatigue life, it is verified that the 3S3 six-axle truck is responsible for most of load effects getting close to the percentage of $99.99 \%$. Hence, after the evaluation of the sixaxle vehicles associated with the percentage considered, the model in Figure 21 is proposed for the Brazilian live load model for unlimited fatigue life. 


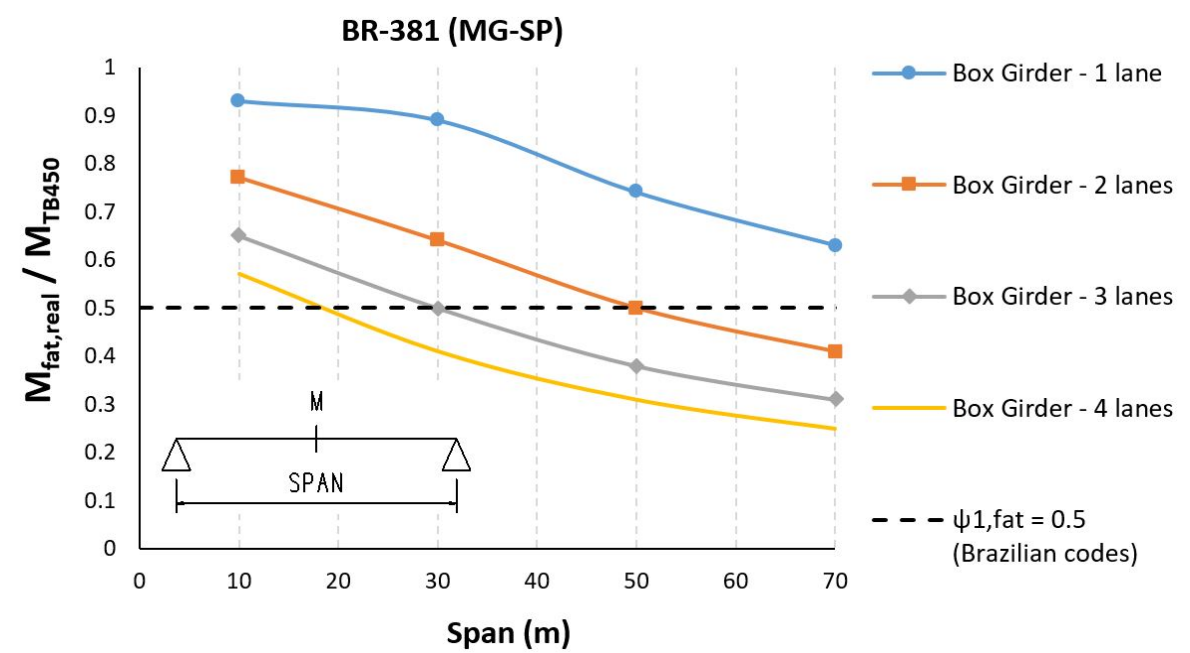

Figure 13. Bias factors for bending moment at mid-span in simply supported box-girder bridges - BR-381 (MG-SP).

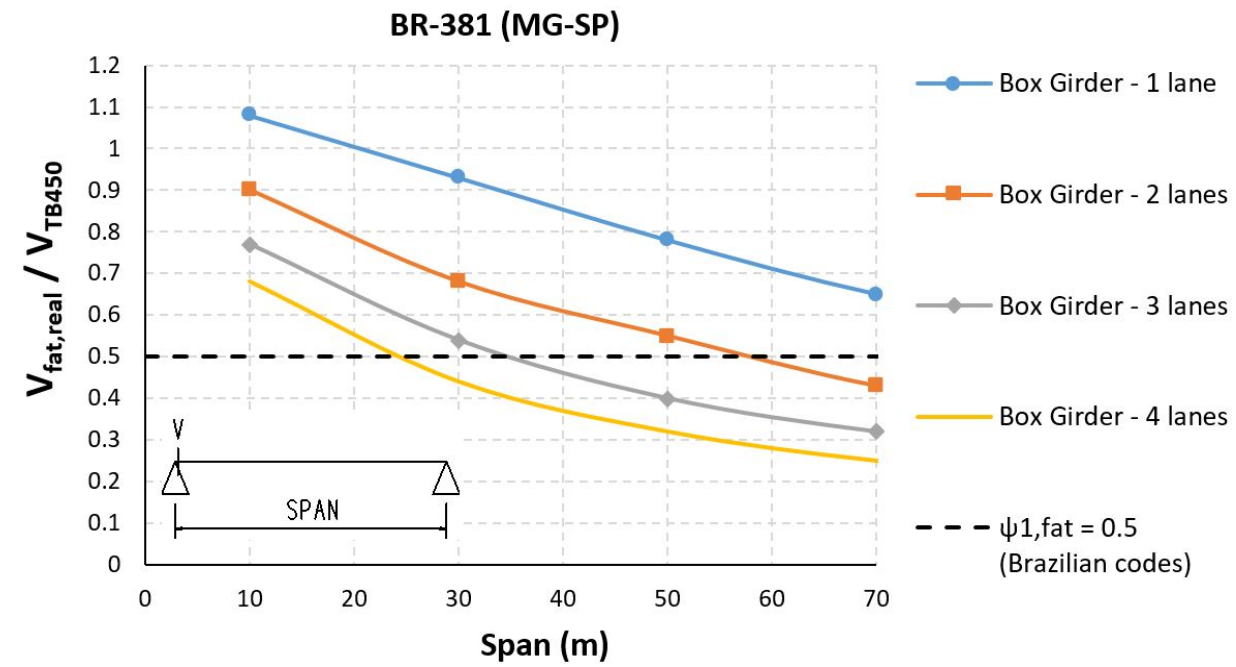

Figure 14. Bias factors for shear force at support in simply supported box-girder bridges - BR-381 (MG-SP).

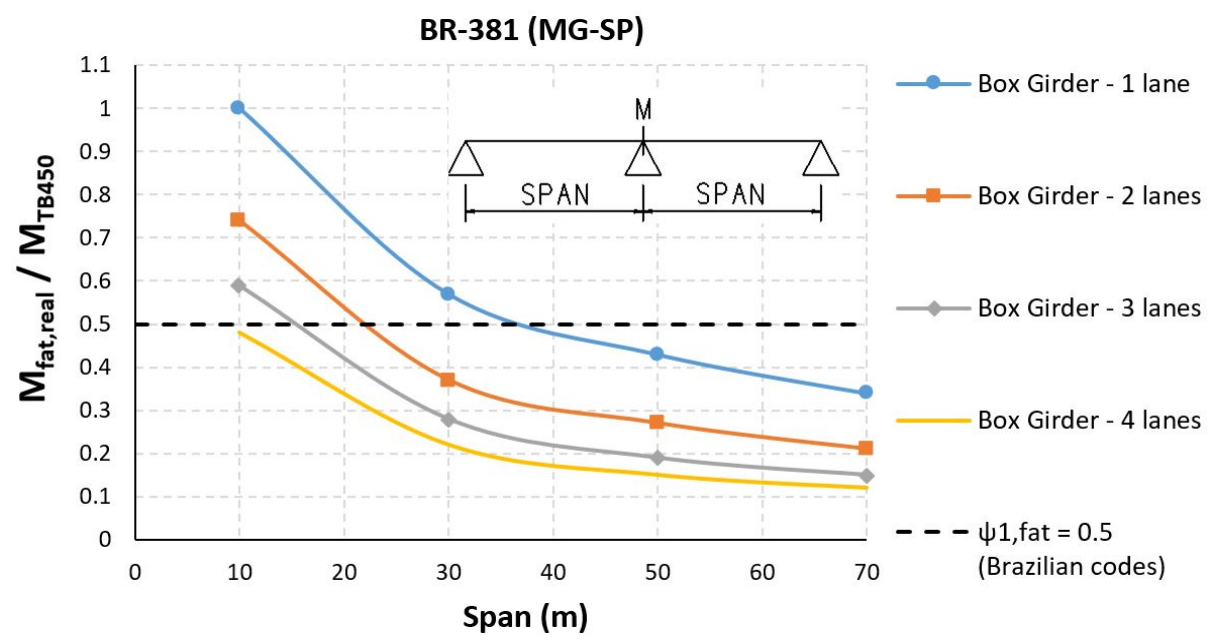

Figure 15. Bias factors for bending moment at support in continuous box-girder bridges - BR-381 (MG-SP). 


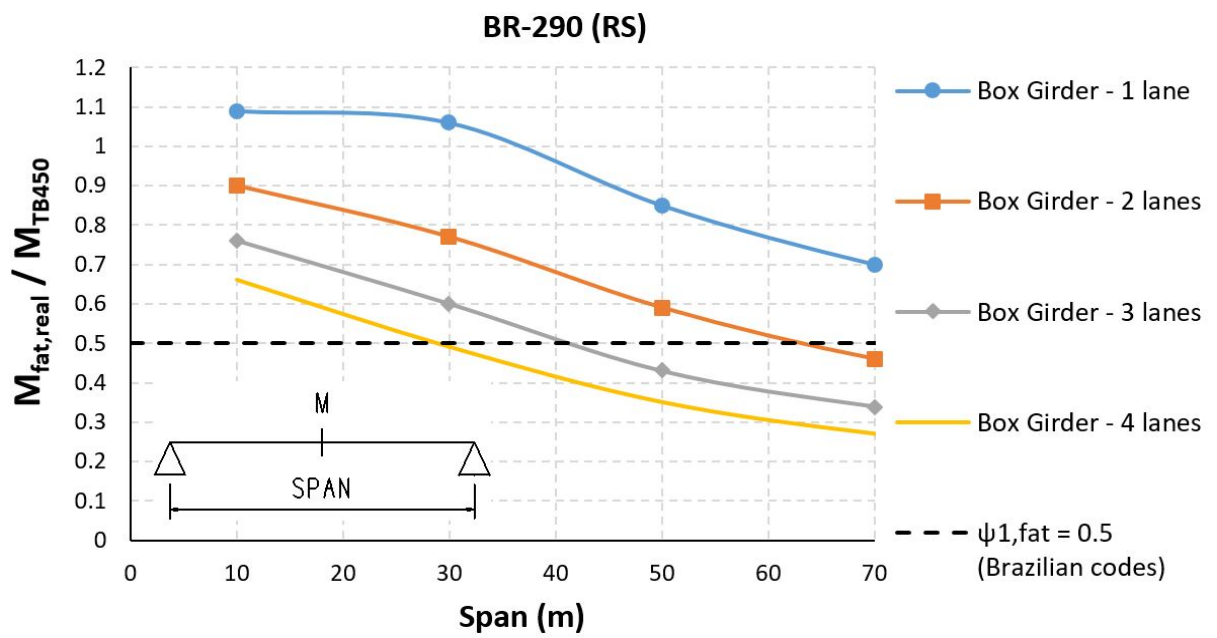

Figure 16. Bias factors for bending moment at mid-span in simply supported box-girder bridges - BR-290 (RS).

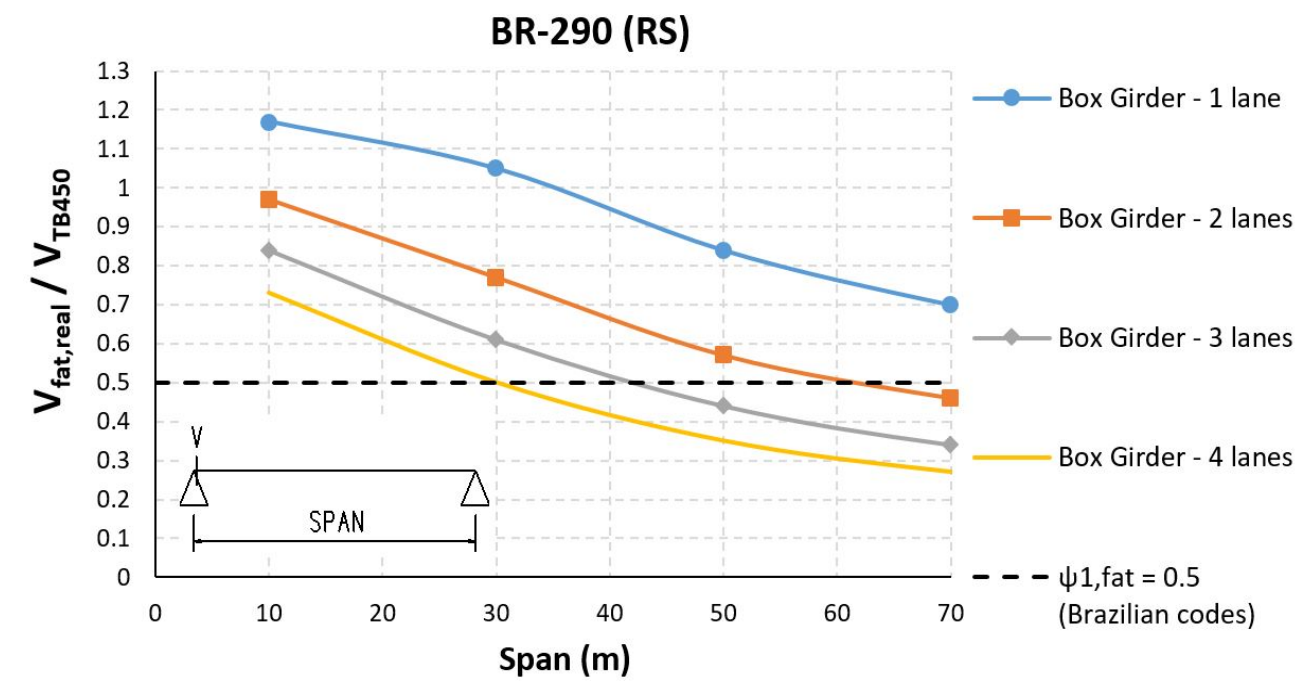

Figure 17. Bias factors for shear force at support in simply supported box-girder bridges - BR-290 (RS).

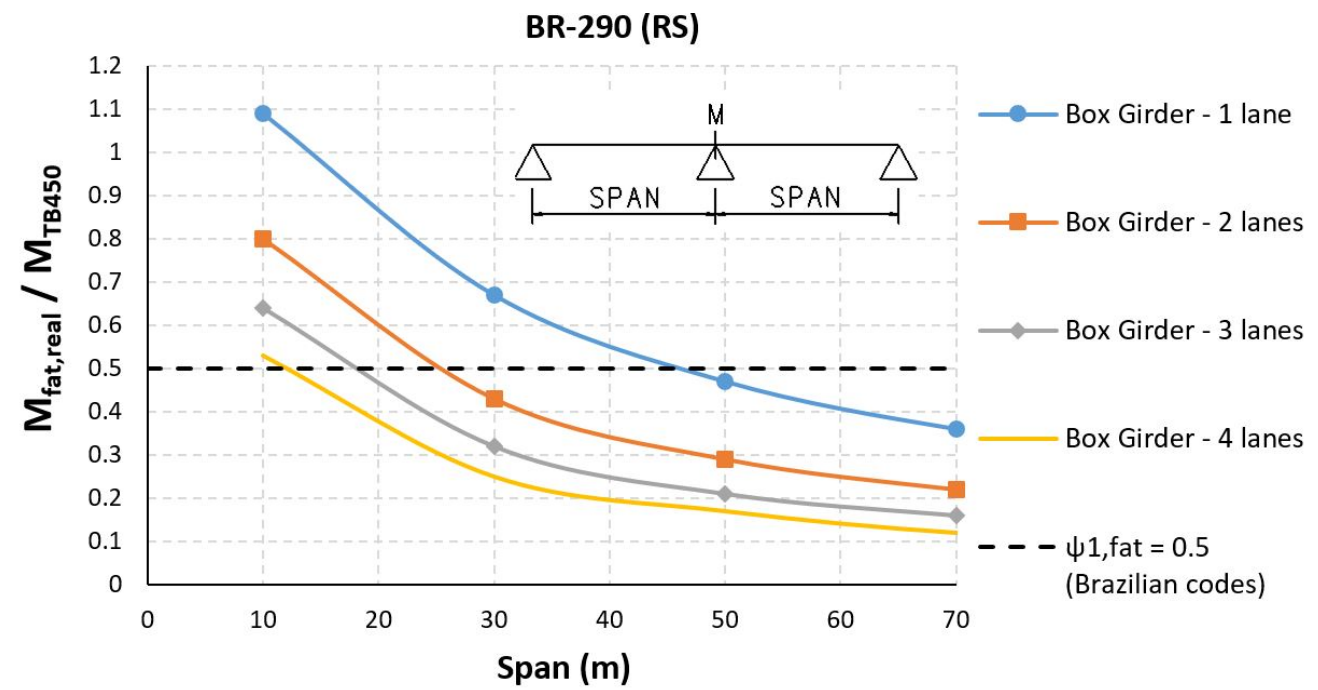

Figure 18. Bias factors for bending moment at support in continuous box-girder bridges - BR-290 (RS). 


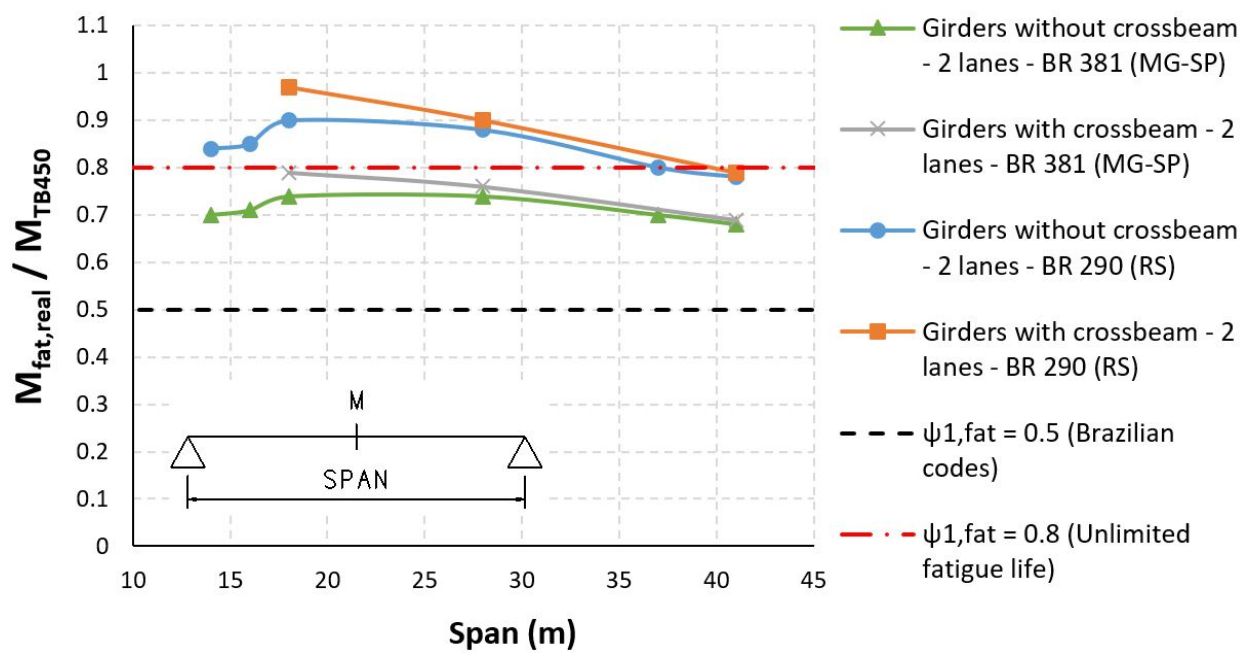

Figure 19. Bias factors for bending moment at mid-span in simply supported girder bridges.

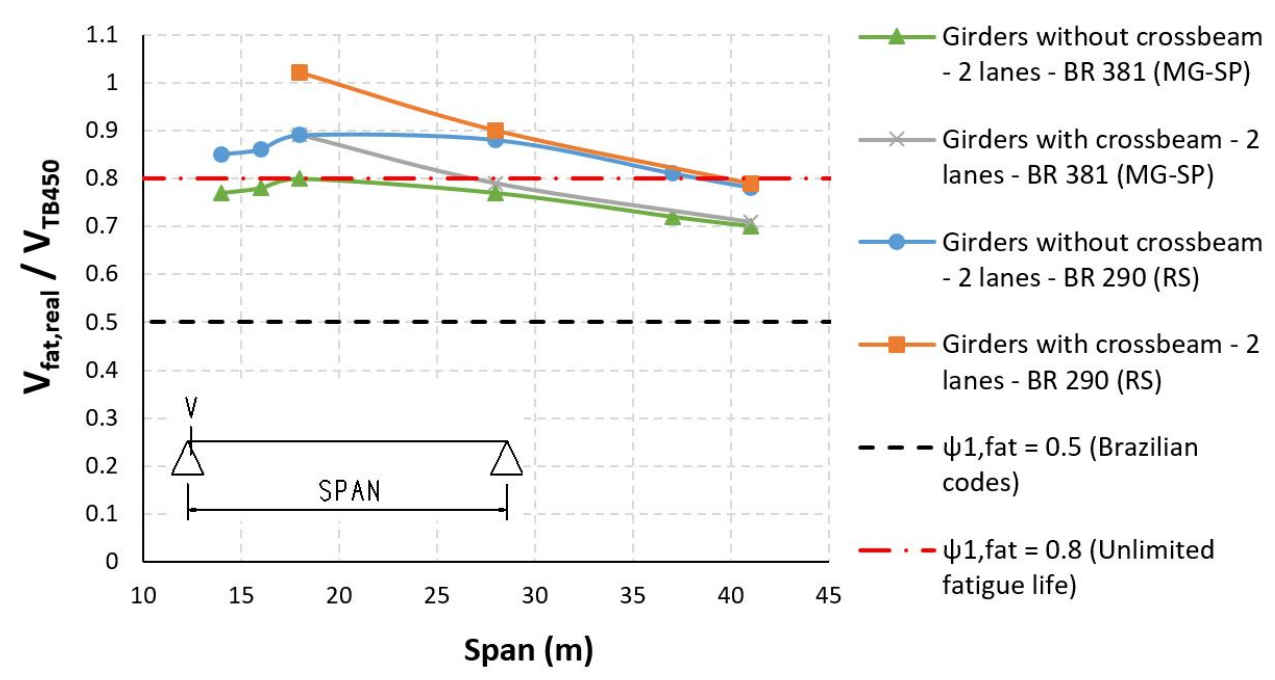

Figure 20. Bias factors for shear force at support in simply supported girder bridges.

Although the trucks associated with the $99.99 \%$ percentage exceed the legal weight, it was used the weight of $500 \mathrm{kN}$ for design truck, which is in accordance with the value of the Brazilian law $(509.25 \mathrm{kN}$, as shown in Figure 7). After the evaluation of the proposed model in relation to the current traffic data, a weighting coefficient is proposed for the loads according to the bias factors obtained.

The proposed model considers the design truck centralized in a $3.5 \mathrm{~m}$ wide design lane. This lane is independent of the road lanes and assumes any position in the entire highway, in the most unfavorable way, including shoulders and clearances. This most unfavorable cross-sectional position ensures that, for girder bridges, the model satisfies even a possible traffic lane leaning against the barrier. For girder bridges where the traffic lane does not touch the barrier, the model is conservative. For box girder bridges, the transverse positioning of the loads does not influence the longitudinal load effects of bending moment and shear force. It is interesting to point out that the load effects of the proposed model do not depend on the number of road lanes, since the distributed loading is not considered. This is consistent with the load effect from actual traffic.

Figures 22 and 23 show the bias factors for the proposed model for the Fernão Dias and BR-290 highways. It is verified that the bias factors are more uniform and vary around the mean value of 1.7. Thus, this work proposes a fatigue coefficient $\gamma_{\text {fad }} .=1.7$ to be applied to the live load model. 


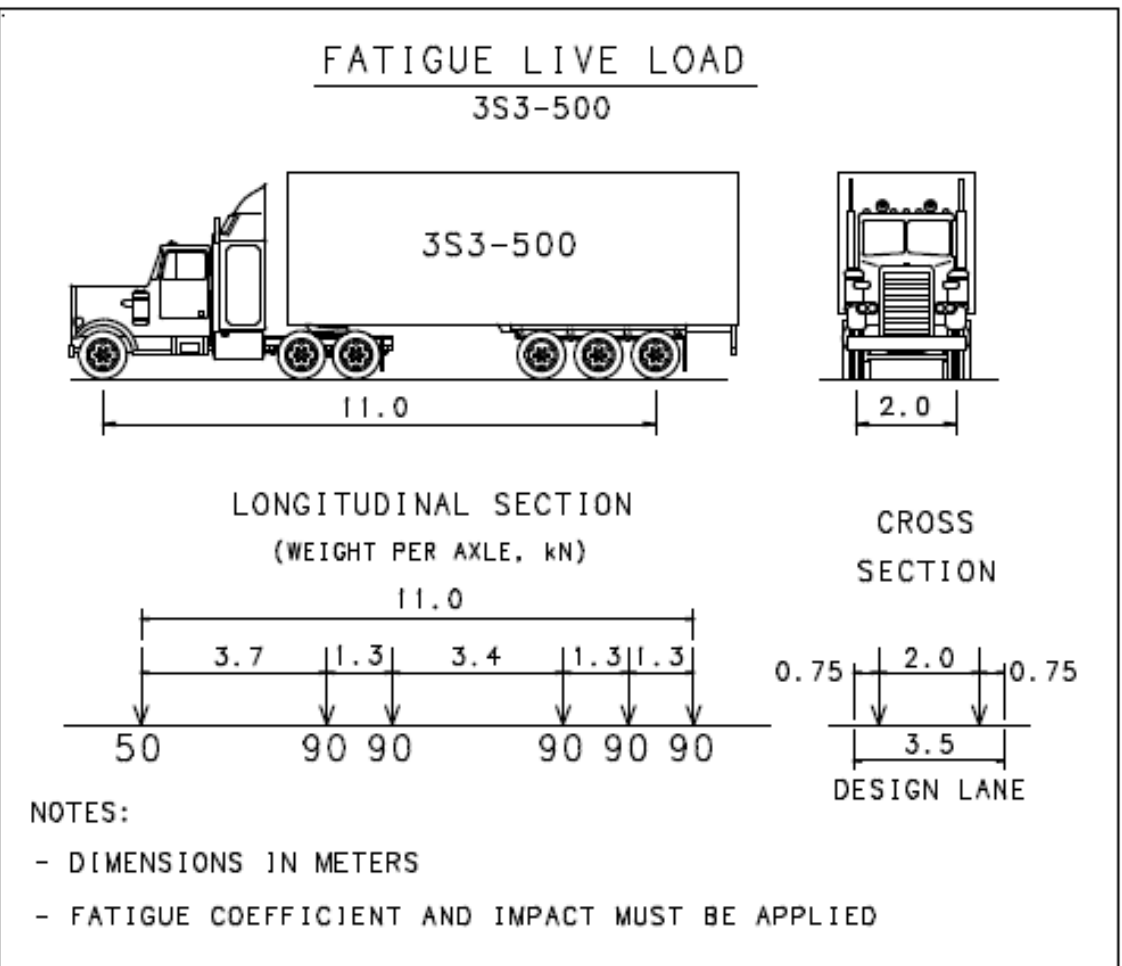

Figure 21. Brazilian live load model proposal for unlimited fatigue life.

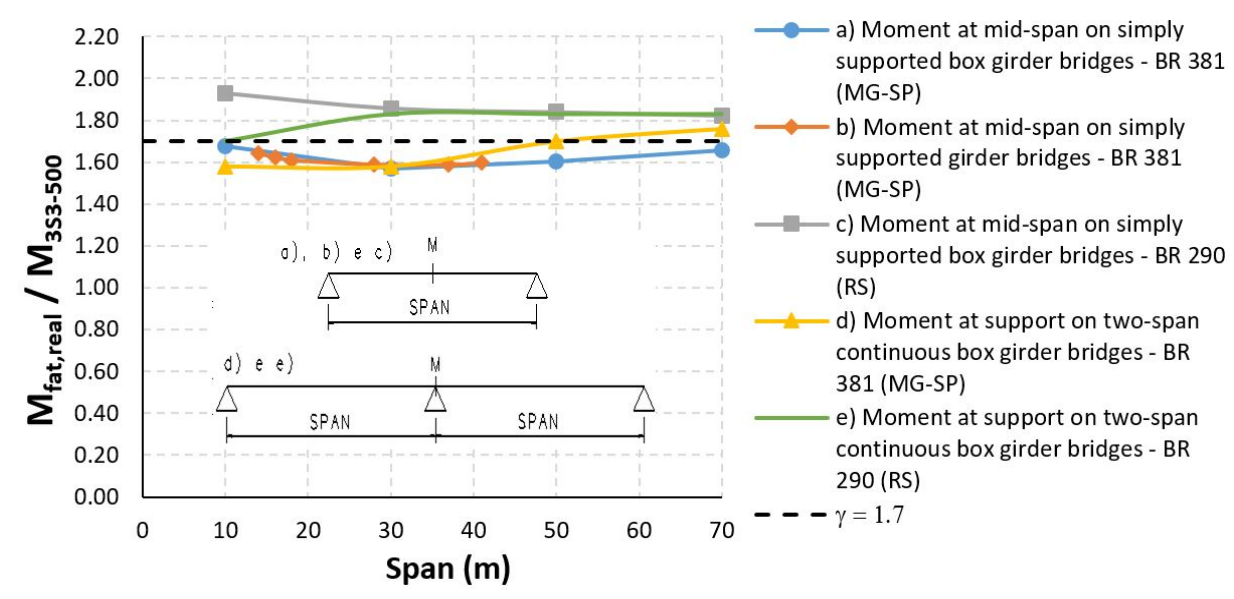

Figure 22. Bias factors for bending moment related to the proposed model.

The proposed model does not consider the impact, which must be studied separately. In the absence of dynamic analysis studies, one option is the vertical impact coefficient (CIV) of NBR 7188 [1]. The number of lanes coefficient (CNF) should not be applied, since the truck is considered in a single design lane.

It is important to point out that the proposed model was developed through the analysis of longitudinal load effects. Thus, for slabs and crossbeams, for example, additional studies are required. In addition, the model is appropriate only for new bridge designs that consider unlimited fatigue life.

It is worth remarking that the proposed live load model and the fatigue coefficient can be reassessed by analyzing more databases and with reliability studies. For the AASHTO LRFD [4] calibration, for instance, Wassef et al. [9] used 15 WIM stations, where the ADTT varied from 97 to 4590. The authors evaluated the bias factors in terms of bending moment for simply supported and continuous bridge for five span lengths $(9,18,27,36$ and 61 meters). The average bias factors varied from 1.34 to 2.07. The average bias factor, considering all stations and spans, was 1.74. After the 
statistical analysis of the bias factors, the authors recommended a fatigue coefficient equal to 2.0 to be applied to the live load model. The coefficient adopted by AAHSTO LRFD [4], however, was 1.75.

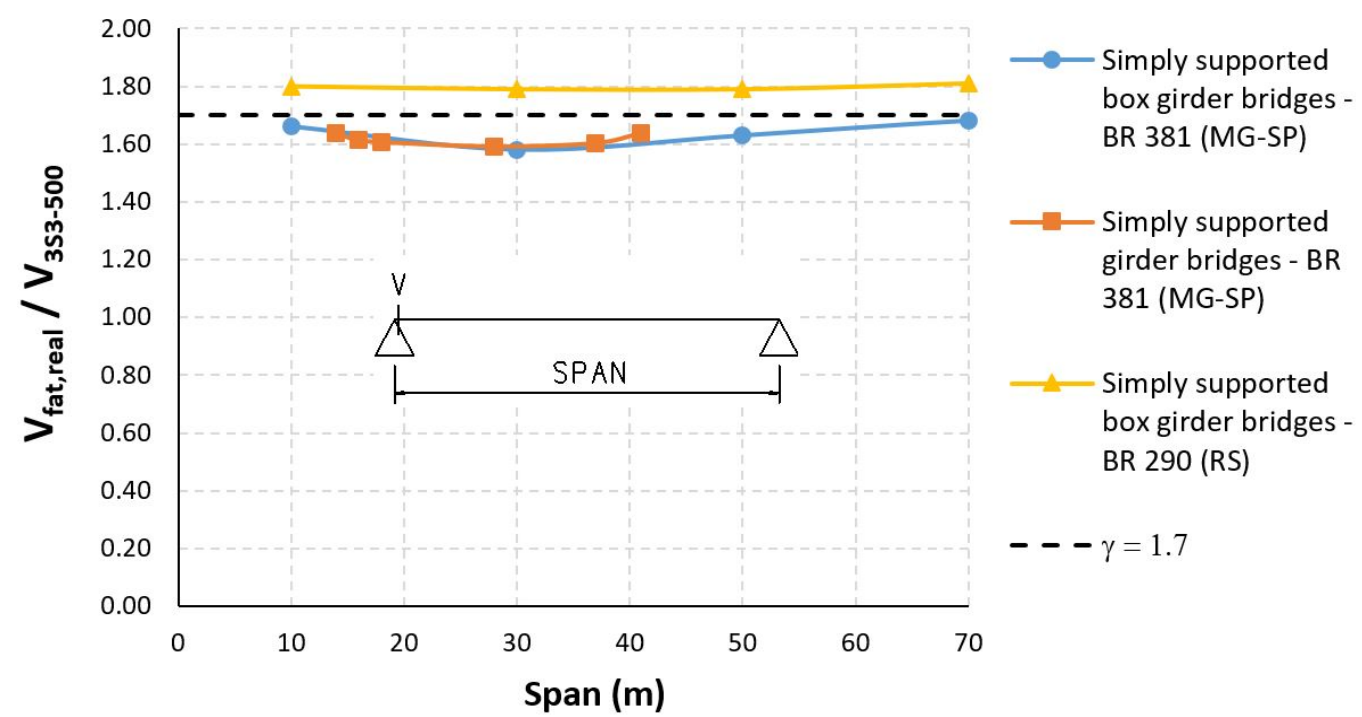

Figure 23. Bias factors for shear force related to the proposed model.

\section{COMPARISON OF MODELS}

In Figures 24 to 26, a comparison between the proposed model and the NBR 7188 [1] model is presented. The box girder section is considered, as shown in Figure 9, and fatigue and impact coefficients are applied. The Ftool program [18] was used for this. The impact coefficient of NBR 7188 [1], which is also applied to the proposed model, is calculated according to expression (2), where "L" is the span length. For the NBR 7188 [1] model, the number of lanes coefficient (CNF) also applies. The fatigue coefficients of the proposed model and the NBR 7188 [1] are 1.7 and 0.5 , respectively.

$$
C I V=1+1.06\left(\frac{20}{L+50}\right) \leq 1.35
$$

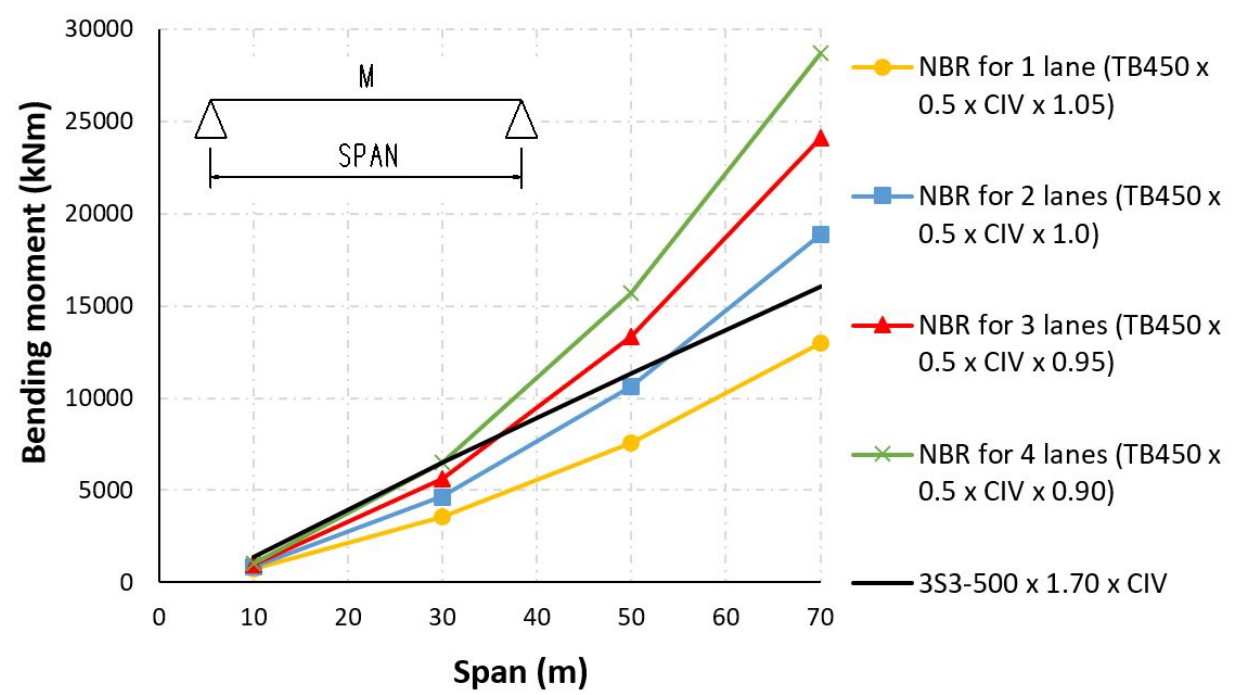

Figure 24. Comparison between models for maximum bending moment at span in simply supported bridges. 


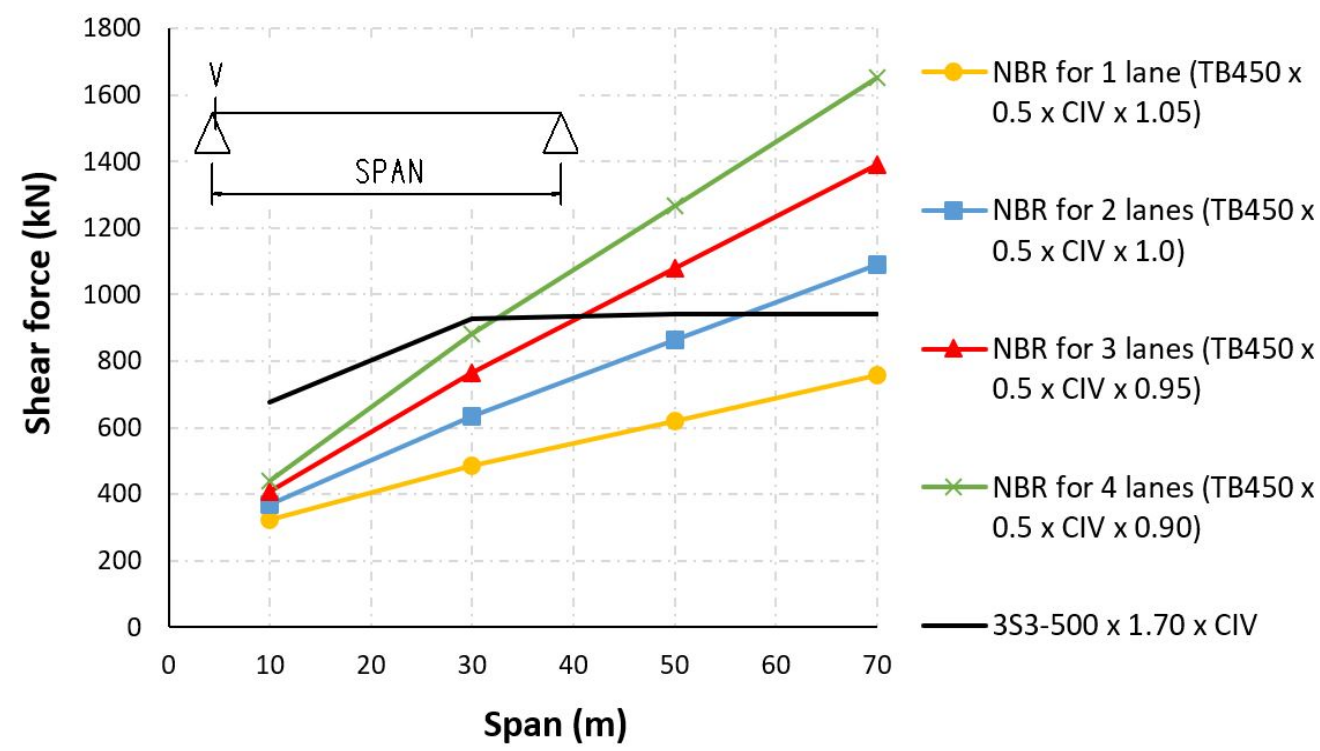

Figure 25. Comparison between models for shear force at support in simply supported bridges

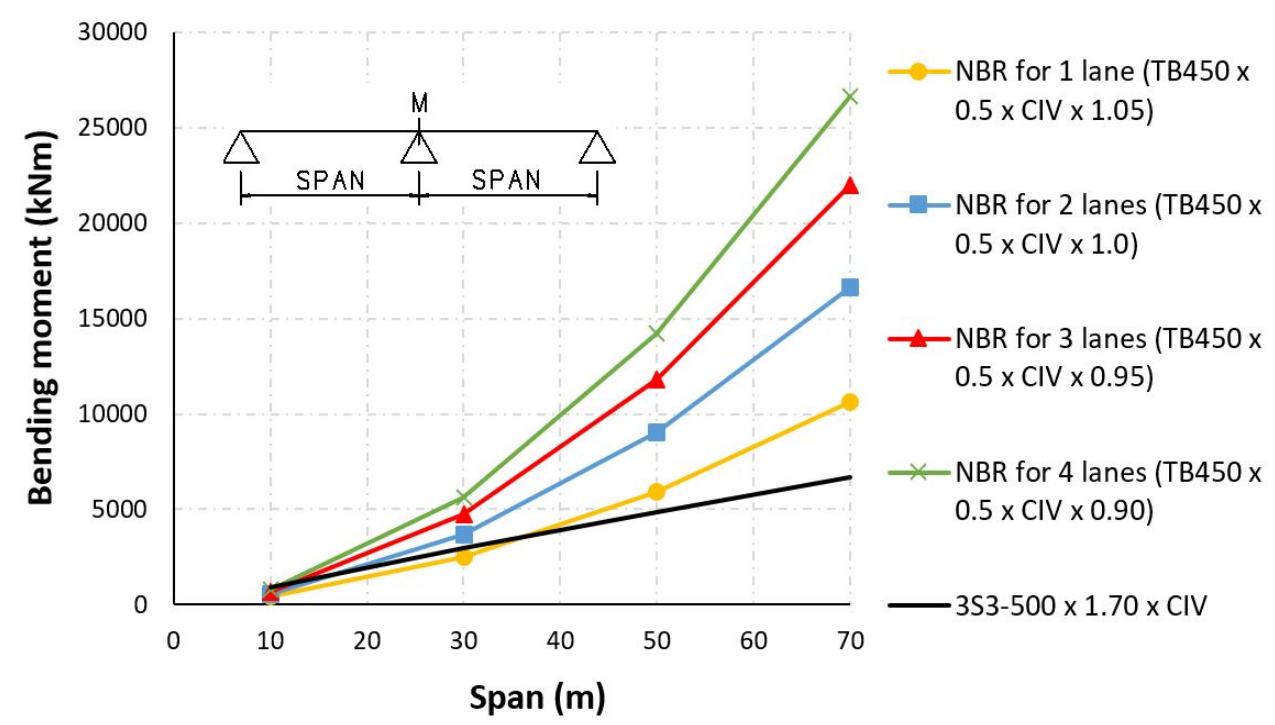

Figure 26. Comparison between models for bending moment at support in continuous bridges.

For short spans (up to $30 \mathrm{~m}$ ), up to four traffic lanes, it is verified that, in terms of positive bending moment and shear force, the proposed model presents higher load effects. As the deck width or the span length increase, the proposed model tends to present lower load effects. For simply supported bridges with two traffic lanes, for example, the proposed model presents higher load effects up to 50-m span, approximately. For the negative moment in continuous bridges, it appears that, in general, the proposed model presents lower load effects. In this case, the proposed model presents higher load effects only for bridges up to 40-m span with one traffic lane, or for short spans (up to $10 \mathrm{~m}$ ) up to four traffic lanes. The fact that the current Brazilian model is conservative for bridges with larger extensions and wider decks, is mainly due to the distributed load.

\section{FINAL CONSIDERATIONS AND CONCLUSIONS}

This work performed an assessment of the Brazilian live load model for fatigue in highway bridges. The present analysis considered real traffic data from two different HS-WIM stations located in two major highways in Brazil: BR381 and BR-290. This paper also proposed a new fatigue live load model for Brazilian highway bridges. Under the 
consideration of unlimited fatigue life approach, bias factors were estimated. A direct comparison between models was presented. Based on this work the following conclusions can be made:

- The current Brazilian live load model does not present uniform bias fators for different span lengths. For large span and multiple lanes bridges, the TB450 presents results that do guarantee unlimited fatigue life for the current truck traffic. On the other hand, for short span bridges, especially with one or two lanes, the current model can not guarantee the same.

- For simply supported girder bridges up to 40-m span, with two lanes (most Brazilian bridges), the factor of 0.8 for TB450 corresponds better to the unlimited fatigue life approach.

- The proposed model, which has a design vehicle more similar to the current Brazilian trucks, presents more uniform bias factors that are consistent with the current traffic.

- For short span bridges up to four lanes, the proposed model presents higher load effects than the ones from the current Brazilian live load model. As more lanes are add or the span length increases, the proposed model tend to present lower load effects compared to TB450.

It is important to note, however, that these findings do not conclude on the safety of the Brazilian live load model, but that it may not guarantee an unlimited fatigue life. To analyze the safety level of the current model and the proposed model, further studies are needed to assess reliability indexes and fatigue life in steel and concrete bridges. In addition, data from more Brazilian highways can be considered.

\section{ACKNOWLEDGEMENTS}

The authors gratefully acknowledge the financial support provided by CNPq and CAPES. The authors are grateful to Arteris S.A., ANTT, and Professor Lélio Brito (UFRGS).

\section{REFERENCES}

[1] Associação Brasileira de Normas Técnicas, Carga Móvel Rodoviária e de Pedestres em Pontes, Viadutos, Passarelas e Outras Estruturas, NBR 7188, 2013.

[2] W. Pfeil, Pontes em Concreto Armado. Rio de Janeiro, RJ, Brasil: Livros Técnicos e Científicos, 1979.

[3] European Committee for Standardization, Eurocode 1 - Actions on Structures - Part 2: Traffic Loads on Bridges, 2003.

[4] American Association of State Highway and Transportation Officials, AASHTO LRFD Bridge Design Specifications, 2017.

[5] H. J. M. Baroni, "Simulação da vida útil de fadiga do concreto em vigas de tabuleiro de pontes em função do fluxo de veículos pesados," Ph.D. dissertation, Esc. Eng., Univ. Federal do Rio Grande do Sul, Porto Alegre, Brasil, 2010. [Online]. Available: https://www.lume.ufrgs.br/handle/10183/26005

[6] J. F. S. Rodrigues, J. R. Casas, and P. A. O. Almeida, "Fatigue-safety assessment of reinforced concrete (RC) bridges: application to the Brazilian highway network," Struct. Infrastruct. Eng., vol. 9, no. 6, pp. 601-616, Jun 2013., http://dx.doi.org/10.1080/15732479.2011.598939.

[7] F. L. Santos and M. S. Pfeil, "Desenvolvimento de modelo de cargas móveis para verificação de fadiga em pontes rodoviárias," in An. VII Congr. Brasileiro Pont. Estrut., Rio de Janeiro, RJ, Brasil, May 21-23, 2014. [Online]. Available: http://www.abpe.org.br/trabalhos/trab_36.pdf

[8] ACI Committee 215, Considerations for Design of Concrete Structures Subjected to Fatigue Loading, ACI 215R-74, 1992.

[9] W. G. Wassef, H. Nassif, D. Mertz, and A. S. Nowak, Calibration of AASHTO LRFD Concrete Bridge Design Specifications for Serviceability, NCHRP Project 12-83. Washington: National Academy of Sciences, 2014. [Online]. Available: https://www.nap.edu/catalog/22407/calibration-of-aashto-lrfd-concrete-bridge-design-specifications-for-serviceability

[10] L. Sanpaolesi and P. Croce, Handbook 4 - Design of Bridges - Guide to Basis of Bridge Design Related to Eurocodes Supplemented by Practical Examples, Leonardo da Vinci Pilot Project CZ/02/B/F/PP-134007, 2005.

[11] Associação Brasileira de Normas Técnicas, Projeto de Estruturas de Concreto - Procedimento, NBR 6118, 2014.

[12] A. C. R. Laranjeiras, "Fadiga das estruturas de concreto," in An. II Simp. EPUSP sobre Estrut. Concr., São Paulo, SP, Brasil, 1990.

[13] Associação Brasileira de Normas Técnicas, Projeto de Pontes Rodoviárias de Aço e Mistas de Aço e Concreto, NBR $16694,2020$.

[14] Associação Brasileira de Normas Técnicas, Ações e Segurança nas Estruturas - Procedimento, NBR 8681, 2003.

[15] E. L. Portela "Analysis and development of a live load model for Brazilian concrete bridges based on WIM data," Ph.D. dissertation, Polytech. Sch., Univ. São Paulo, Brazil, 2018. [Online]. Available: https://www.teses.usp.br/teses/disponiveis/3/3144/tde-11122018151658/pt-br.php

[16] L. A. T. Brito and A. Bock, Estudo do Espectro de Cargas dos Veículos Comerciais Rodantes na BR-290/RS, Freeway, Através do Uso da Técnica do Weigh-in-Motion (WIM). Porto Alegre, RS, Brasil, Doc. No 12-0020, Apr. 2013. 
[17] F. R. Stucchi, Pontes e Grandes Estruturas. São Paulo, SP, Brasil: Esc. Politéc., Univ. São Paulo, 2006.

[18] L. F. Martha, Ftool: Interactive-Graphics Program for Structural Analysis, Version 4.00, 2018. [Online]. Available: https://webserver2.tecgraf.puc-rio.br/ftool

[19] A. Nowak and K. Collins, Reliability of Structures. New York, NY, USA: McGraw-Hill, 2013.

Author contributions: ALC: conceptualization, methodology, formal analysis, writing, proofreading; ELP: data curation, writing review, proofreading; TNB: data curation, funding acquisition, supervision, proofreading.

Editors: Bernardo Horowitz, José Luiz Antunes de Oliveira e Sousa, Guilherme Aris Parsekian. 